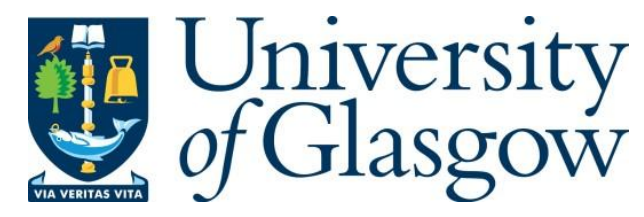

Yang, L., Erdem, E., Zare-Behtash, H., and Kontis, K. (2012) Pressuresensitive paint on a truncated cone in hypersonic flow at incidences. International Journal of Heat and Fluid Flow, 37 . pp. 9-21. ISSN 0142-727X(doi:10.1016/j.ijheatfluidflow.2012.05.004)

Copyright () 2012 Elsevier

A copy can be downloaded for personal non-commercial research or study, without prior permission or charge

Content must not be changed in any way or reproduced in any format or medium without the formal permission of the copyright holder(s)

When referring to this work, full bibliographic details must be given

http://eprints.gla.ac.uk/84607/

Deposited on: 07 January 2014

Enlighten - Research publications by members of the University of Glasgow http://eprints.gla.ac.uk 


\title{
Pressure-Sensitive Paint on a Truncated Cone in Hypersonic Flow at Incidences
}

\author{
L. Yang, E. Erdem, H. Zare-Behtash, ${ }^{*}$ and K. Kontis \\ School of Mechanical, Aerospace and Civil Engineering, University of Manchester, UK \\ S. Saravanan \\ Department of Aerospace Engineering, Indian Institute of Science, Bangalore, India
}

\begin{abstract}
The flow over a truncated cone is a classical and fundamental problem for aerodynamic research due to its three-dimensional and complicated characteristics. The flow is made more complex when examining high angles of incidence. Recently these types of flows have drawn more attention for the purposes of drag reduction in supersonic/hypersonic flows. In the present study the flow over a truncated cone at various incidences was experimentally investigated in a Mach 5 flow with a unit Reynolds number of $13.5 \times 10^{6} \mathrm{~m}^{-1}$. The cone semi-apex angle is 15 degrees and the truncation ratio (truncated length/cone length) is 0.5. The incidence of the model varied from -12 to 12 degrees with 3 degrees intervals relative to the free stream direction. The external flow around the truncated cone was visualised by colour schlieren photography, while the surface flow pattern was revealed using the oil flow method. The surface pressure distribution was measured using the anodized aluminium pressure-sensitive paint (AA-PSP) technique. Both top and side views of the pressure distribution on the model surface were acquired at various incidences. AA-PSP showed high pressure sensitivity and captured the complicated flow structures which correlated well with the colour schlieren and oil flow visualisation results.
\end{abstract}

\footnotetext{
${ }^{*}$ Hossein.Zare-Behtash@glasgow.ac.uk
} 


\section{INTRODUCTION}

The cone is one of the most fundamental and classical geometries for aerodynamics research. When supersonic/hypersonic flow passes over the cone/truncated cone, it presents an opportunity to study the attached/detached bow shock wave, expansion wave, internal shock wave, and flow separation. At high angles of incidence, the flow pattern becomes even more complicated consisting of three-dimensional boundary layer development with vortical flow. Significant amounts of work ${ }^{1-5}$ have been carried out on the investigation of supersonic/hypersonic flow around inclined cone or cone-cylinder configurations. Three-dimensional boundary layer development on a 12.5 degrees semi-apex sharp cone was experimentally investigated by Rainbird ${ }^{6}$ at a series of yawed incidences in supersonic flows. The symmetrical vorticities are found on the leeward side of the cone and the development of such vortices structures are believed to be a gradual and essentially conical process with increasing incidence. A Computational Fluid Dynamic (CFD) test was conducted at a similar condition by Adams ${ }^{7}$ but was not found the trace of vortices.

Previous studies have shown that the flat faced blunt nose is beneficial for increasing the static stability and resistance to erosion for re-entry vehicle forebody bluntness. ${ }^{8}$ Recently, the truncated cone geometry has attracted many researchers for drag reduction in the regime of supersonic/hypersonic flow using direct energy deposition techniques because of its unique shape and resulting flow patterns. ${ }^{9-12}$ The energy source can either be a laser pulse or plasma. This is attributed to the large effectiveness of drag reduction using blunt bodies in supersonic/hypersonic flow, compared to the sharp model. ${ }^{13}$

A series of truncated cones were tested at Mach numbers of 2 to 4 at various angles of attack by Brodetsky (et al). ${ }^{14}$ The pressure distribution was measured using pressure taps and the shock wave pattern visualised by schlieren photography. The pressure distribution along the circumferential rays revealed the flow separation at high angles of attack. The pressure on the conical surface was found to be related to the existence of an internal shock wave. A detailed understanding of the flow structures around truncated cone is crucial for direct energy drag reduction techniques development and also important for verification and validation of CFD codes, especially at high incidence angles. However, investigation of such flows is mostly done by the conventional pressure measurement and oil flow visualisation which limits in-depth understanding of the complicated flow physics. The resolution of surface pressure obtained using discrete pressure taps is not sufficient to distinguish the complicated flow patterns. The pressure-sensitive paint (PSP) technique provides a novel and 
powerful flow diagnostics tool to study such complicated flow features.

PSP is a photochemical sensor based on the oxygen quenching mechanism. Emission from the PSP paint can be converted to pressure using the proper a priori or in situ calibration. The advantage of the PSP technique is the capability of providing global surface pressure with high spatial resolution without the requirement of a large number of pressure taps. ${ }^{15}$ Additionally, the working mechanism of PSP makes the quantitative measurement of the surface pressure almost instantaneous.

The successful application of PSP has been reported in both low and high speed flows. ${ }^{16-25}$ However, the application of PSP in hypersonic flowfields still faces some challenges such as short duration test times and low freestream pressures level. ${ }^{26,27}$ The anodized aluminium pressure sensitive paint (AA-PSP) is a new branch of PSP with unique characteristics. Microscopic pores are created on the aluminium test model by an electro-chemical process known as anodization. Oxygen sensitive molecules, called luminophores, are physically absorbed into these micro pores, and interact with the oxygen molecules without the obstruction of the binder material. This mechanism leads to the fast response and high pressure sensitivity characteristics of AA-PSP, compared to polymer based PSPs. The improvement of the response characteristics has been studied and compared to the other polymer type PSP on the sample test. ${ }^{28,29}$ The AA-PSP technique has also been applied in the unsteady flow diagnostics ${ }^{30-32}$ as well in steady flowfield. ${ }^{27,33,34}$ The results qualitatively captured the complex flow structures such as flow separation, re-attachment, and shock-shock interaction. The measured pressure also showed very good quantitative agreement with the pressure transducer data.

In the current study, the AA-PSP technique is utilised to map the surface pressure distribution of the flow regime around a truncated cone in Mach 5 flow. Colour schlieren photography is employed to investigate the external flow, while the surface flow pattern is visualised using the oil flow method for comparison.

\section{EXPERIMENTAL SETUP}

\section{A. Wind Tunnel Facility}

The wind tunnel facility used in the current research is an intermediate blow-down hypersonic tunnel having a test time of 7.5 seconds. The system mainly consists of high pressure vessel, vacuum tank, electric heater, axisymmetric nozzle, working section and auxiliary system such as pumping, 
pressure supply and water cooling system. The hypersonic wind tunnel system is schematically shown in Figure 1. The wind tunnel is equipped with five axisymmetric nozzles, which are Mach 4, Mach 5, Mach 6 and two Mach 5 nozzles with centre-bodies. For the current research, the Mach 5 contoured nozzle without centre-body was used. The gas temperature can be raised from ambient to $700 \mathrm{~K}$ to avoid condensation in the test section. Unit Reynolds number of $4.5 \times 10^{6} \mathrm{~m}^{-1}$ to $16.5 \times 10^{6} \mathrm{~m}^{-1}$ can be obtained by varying supply pressure and heater temperature. The tunnel test section is a free-jet type with an axisymmetric nozzle exit of $152 \mathrm{~mm}$ diameter. Two $195 \mathrm{~mm}$ diameter quartz windows are used on either side of the wind tunnel test section to provide an optical access for flow visualisation.

A three component force balance system is installed inside the test section which includes the measurement sting and support arc. The arc allows the angle of attack to vary from -20 to 20 degrees relative to the freestream direction. Further detail of the facility and testing equipments are reported by Erdem et al. ${ }^{12,35}$ Experimental conditions of total pressure and temperature are monitored using the stagnation pitot and thermocouple probe installed in the settling chamber. A Kulite pressure transducer (XTE-190M, 0 to 7 bar) is used to measure the stagnation pressure and data is acquired by National Instruments (NI) system and operated using Labview. A typical total pressure, pitot pressure and temperature signal are shown in Figure 2.

\section{B. Test Model}

The test model used in the present study is a 30 degrees apex truncated cone followed by a cylinder portion. The cone is truncated by means of removing the tip from the nose (50 percent of the nose cone length, i.e., $29 \mathrm{~mm}$ ). This model is fabricated from aluminium alloy 6061, which can be anodized efficiently for the PSP application and has stronger mechanical properties compared to soft pure aluminium. The front edge of the model nose and the frustum/cylinder junction are designed as sharp edges with a tolerance of $\pm 0.02 \mathrm{~mm}$. However, the model was smoothed by the sand paper during the model preparation. The dimensions of the truncated cone model with AA-PSP coating is shown in Figure 3. The model is mainly anodized according to Sakaue's procedure. ${ }^{36}$ The aluminium truncated model is degreased by wiping with ethanol and then chemically polished by immersion in a $2 \mathrm{wt} \%$ sodium hydroxide solution for 5 minutes. After being washed with distill water and dried, the model is then connected to the anode of a DC power supply and immersed in $1 \mathrm{M}$ sulfuric acid solution for anodization. The temperature of the solution was left at room temperature rather than the 
constant low temperature recommended by Kameda et al. ${ }^{29}$ and Sakaue. ${ }^{36}$ A uniform porous surface is obtained after 30 minutes of anodization. A post-treatment process was subsequently performed by immersing the model in $5 \%$ phosphoric acid solution to remove the relative soft alumina layer. Eventually, the anodized model is dipped into the dye solution to obtain a uniform luminescent coating after post-treatment. The successful anodization has been reported by Yang et al. ${ }^{37,38}$ using an identical procedure. The dye solution is $\left[\mathrm{Ru}(\mathrm{dpp})_{3}\right]^{2+}$ diluted in dichloromethane solvent with a concentration of $0.3 \times 10^{-3} \mathrm{~mol} / \mathrm{L}$ as suggested by Gregory et al. ${ }^{26}$ A scanning electron microscope (SEM) image of the anodized aluminium surface is shown in Figure 4, where the microscopic pores are clearly evident. The wind tunnel flow conditions for the tests are summarised in Table I.

\section{Flow Visualisation}

A Z-type schlieren optical system is employed for flow visualisation which consists of a light source, two $20.3 \mathrm{~cm}$ parabolic mirrors with $182.9 \mathrm{~cm}$ focal length and a digital Canon SLR camera. The internal halogen bulb of Palflash 501 (Pulse Photonics), which is originally used for light beam alignment purpose, is utilised as the continuous light source. The light generated from the light source is cut by a $2 \mathrm{~mm}$ wide slit and collimated by the first mirror. The parallel beam passes through the test section and is reflected by the second parabolic mirror to the focus spot. A knife edge is located at the focus point to cut the light in order to adjust the sensitivity. In the present research, a "tricolour filter" containing three parallel colour strips is used to replace the knife edge for colour schlieren photography. The offset angle between the collimated light beam and light source is set at 10 degrees to prevent coma and astigmatism. The camera is set to continuous shooting mode at $3.5 \mathrm{fps}$ with an exposure time of $1 / 4000$ seconds. The layout of the optical setup is shown in Figure 5.

A fluorescent oil mixture composed of silicone oil, linseed oil, titanium dioxide, oleic acid, and luminescent dye was used for oil flow visualisation. A $0.5 \mathrm{~mm}$ oil mixture blob was placed on a $5 \times 5 \mathrm{~mm}$ matrix drawn on the model surface. Oil dot movement is recorded by a camera during the tunnel running. The setup model with oil dot streaks after test run is shown in Figure 6. 


\section{AA-PSP}

The truncated cone model was supported using a sting mounted on the arc, which allows for the variation of the angle of incidences. A pair of light emitting diode (LED) panels with a peak wavelength of $470 \mathrm{~nm}$ was used as the excitation light source. The utilisation of LEDs eliminates the complicated combinations of filters required in front of the light source as reported by GongoraOrozco et al. ${ }^{39}$ Each LED panel is comprised of $13 \times 10$ LED arrays. The LED panel is placed on each side of test section. A 12 bit LaVision Image Intense CCD camera is used for image acquisition. The main advantage of placing two LED panels, as shown in Figure 7, on both sides of test section is that it can provide a uniform illumination on the surface of model.

The wavelength emitted from the LED panels and emission wavelength of Ruthenium (II) are measured using a spectrometer (Princeton Instruments ICCD spectrometer), shown in Figure 8. Different wavelength filters were required to separate the emission from the illumination. Based on the spectral analysis, a combination of orange $550 \mathrm{~nm}$ long pass and an IR rejection filter were employed in front of the CCD camera. The former allows the transmission of light with $\lambda>550 \mathrm{~nm}$ while the latter rejects light with wavelength longer than $700 \mathrm{~nm}$. The CCD camera is connected to a PC for image acquisition and operated by Davis software.

The PSP image acquisition starts before the test run and records for the entire test duration of 10 seconds with a frame rate of $9 \mathrm{fps}$. Stable flow is established 0.5 seconds after wind tunnel start (see Figure 2). A total of 30 images are chosen from the image sequences after stable flow establishment and then averaged for data processing. The reference image is recorded immediately after the test when the model temperature is close to the temperature distribution during the test. All the tests are conducted in a dark background. Dark images are also recorded which is then subtracted from the test and reference images for dark correction. To compensate for slight model motion, the test image is correlated to the corresponding reference image using a pixel-to-pixel registration method. Afterwards, an intensity ratio image is obtained by dividing the reference image by the correlated test image. Eventually, the intensity ratio is converted to pressure distribution using a calibration curve. A $3 \times 3$ pixels average filter is applied in the processing to smooth the PSP image. The resolution in the PSP image is 10.7 pixels per $\mathrm{mm}$. 


\section{E. Infrared Thermography}

The change of surface temperature distribution in the test duration is measured using infrared thermography. The camera (FLIR ThermaCAM SC 3000) has a temperature range of $-20{ }^{\circ} \mathrm{C}$ to $2000{ }^{\circ} \mathrm{C}$ with accuracy of $\pm 1 \%$. The spectral range of the camera is around 8 to $9 \mu \mathrm{m}$. The camera is installed on the top of the test section and views the model through a Germanium window coated at 3 to $12 \mu \mathrm{m}$. Therefore, only the windward or leeward side of the model surface can be acquired depending on the incidence angle. The model was painted black to increase the surface emissivity, which is estimated to be 0.95 . The transmission ratio of the Germanium window and the test gas is assumed to be 0.97. The surface temperature was recorded in the entire test duration at $50 \mathrm{~Hz}$. The infrared thermography measurements were conducted at identical experimental conditions as the PSP tests.

\section{RESULTS AND DISCUSSIONS}

\section{A. The Structure of the Flowfield}

Figure 9 shows the colour schlieren visualisation of the flow structures around the truncated cone model at -12 degrees incidence. As the hypersonic flow passes over the model, a detached bow shock wave is formed as the truncated cone perturbs the flow. In the vicinity of the truncated cone nose, the freestream flow decelerates to subsonic conditions locally due to the nearly normal shock wave. It is believed that the shock stand-off distance depends on the local Mach number and is independent of the half cone-angle for the truncated cone body. A highly curved shock wave occurs at lower negative incidence angles while the shock wave approaches the model surface on the windward side but departs on the leeward side.

When the flow passes the model nose, the flow overexpansion occurs near the edge of the model nose in the Prandtl-Meyer expansion. ${ }^{14}$ The flow separates close to the edge of the model nose because of the flow overexpansion but re-attaches to the model further downstream. The separation region can be observed on both the leeward and windward sides around the edge which is shown in Figure 9. A larger separation region appears on the leeward side since higher adverse pressure gradients are observed at lower incidences. Also, the origination of the internal shock moves slightly downstream on the leeward side of model.

An internal shock wave is generated due to flow overexpansion and shown in Figure 9. Detailed 
explanation of the formation of the internal shock wave has been reported by Brodetsky. ${ }^{14}$ On the windward side, the internal shock wave interacts with the bow shock wave and is reflected towards the model surface.

\section{B. Surface Flow Pattern}

The surface flow pattern is visualised by the oil flow technique, which has been successfully conducted in hypersonic flow to identify the detail flow structures by Kontis et al. ${ }^{40-42}$ Oil dot movement is recorded during each run from the top of the test section. Figure 10 only displays the luminescent oil flow results at representative angles of incidences (i.e., 0, 6 and 12 degrees) viewed from the top. According to Squire's analysis, ${ }^{43}$ the direction of the oil movement is believed to correlate to the wall shear stress and the pressure gradient. Generally, the oil streaks are longer on the conical surface than the cylinder segment, which corresponds to the high shear stress on the conical surface. At 0 degrees incidence, the oil dot moves parallel to the downstream and there is no sign of crossflow on the surface. At higher incidences, the separation region on the leeward surface starts to appear, which is close to the tip of the truncated model. This separation zone can be seen in Figure 10(b) at 6 degrees and more clearly at 12 degrees incidence in Figure 10(c), where the length of the oil dot movement is shorter than the surrounding streaks. Meanwhile, the oil dot is almost stationary on the cylindrical portion at higher incidences showing the less shear stress or low pressure gradient at this position.

At higher incidence angles, the crossflow is also visible, indicated by the traverse oil streaks from the windward to leeward surface. The transverse flow is caused by the pressure gradient between the windward and leeward surface. The crossflow affected region is more dominant at high angles of attack.

\section{Surface Pressure Distribution}

The AA-PSP calibration is performed inside the test section by varying the pressure and acquiring the corresponding intensity, known as a priori calibration. The advantage of such a calibration is that all the calibration parameters, including the light source, filters, and camera setup are identical to the actual test. This calibration method will reduce the system errors caused by changing the optical components. Figure 11 represents the change of normalised AA-PSP emission intensity ratio 
$\mathrm{I}_{\text {ref }} / \mathrm{I}$ corresponding to the pressure ratio $\mathrm{P} / \mathrm{P}_{\text {ref }}$ increment during a priori calibration, where the reference pressure $\mathrm{P}_{\text {ref }}$ is $2.39 \mathrm{kPa}$. The emission intensity is even over the model surface which further proves the successful anodization and uniform paint application process. It is found that the intensity ratio $\mathrm{I}_{\text {ref }} / \mathrm{I}$ dramatically rises with the pressure ratio $\mathrm{P} / \mathrm{P}_{\text {ref }}$ increment.

The intensity ratio is collected from each AA-PSP image, averaged, and then plotted as a function of pressure ratio, shown in Figure 12. The intensity ratio changes dramatically even for a small pressure rise, as it is evident in both the AA-PSP images and the calibration curve, indicating a high pressure sensitivity of the AA-PSP. The high pressure sensitivity characteristic of AA-PSP is preferable considering the low freestream pressures levels. The calibration data was fitted with a non-linear Stern-Volmer equation shown in Equation (1).

$$
I_{\text {ref }} / I=A+B\left(P_{\text {ref }} / P\right)^{\gamma}
$$

This non-linear equation is based on the absorption-controlled model, which is suggested by Sakaue et al. ${ }^{28}$ for porous PSPs. An accurate fitting can be seen from the calibration curve with adjusted $\mathrm{R}$ square of 0.999 . The calibrated pressure range is slightly lower than the pressure scale in the following discussion. However, by using the absorption-controlled model to curvefit calibration curve, it is believed that the calibration curve will fit the data well in the higher pressure range.

\section{Surface Pressure Mapping from Sideview}

Figure 13 shows the combined colour schlieren photographs and AA-PSP images of the truncated cone model at each incidence. The AA-PSP images capture the complicated flow features which correlate well with the schlieren photographs. High pressure appears on the conical surface since the flow is compressed after the bow shock wave. Downstream of the expansion wave at the junction of frustum and cylinder, the flow is expanded and hence the pressure is relatively lower on the cylindrical portion.

At small incidences, the flow is fully attached to the model surface except the minor separation zone around the edge of the model nose. As the incidence increases, the bow shock wave moves towards to the windward surface. On the contrary, the shock wave on the leeward side departs from the model surface. The separation zone around the edge of the model nose grows on the leeward side but gradually vanishes on the windward side. The expansion wave on the windward side turns-out to be strong but it obscures on the leeward side. With increasing incidence, the pressure on the 
windward surface of truncated cone gradually rises. The rise of surface pressure is evident on the inclined truncated cone surface. However, on the leeward side, the size of the separation zone grows. The increment in size of the separation region is evident in the colour schlieren photograph in the transition of incidence angle from 0 to -12 degrees. The aforementioned phenomena can also be seen in the AA-PSP mapping around the edge of model nose on leeward side.

The high pressure pattern occurs at a specific region on the conical surface close to the edge of the model nose at 0 degrees incidence. The pattern turns to be a more complicated "hourglass" shape at lower negative incidence angles. The normalised circumferential pressure is taken at four different axial locations on the truncated cone model surface. These locations are schematically shown in Figure 14. The first two are located on the conical surface while the last two positions are on the cylindrical portion. The pressure profiles are plotted as a function of circumferential angle and presented in Figure 15. At lower negative incidences, the pressure monotonically decreases with the circumferential angle from the windward to the leeward side. A minimum pressure is found between 90 to 180 degrees, which corresponds to the leeward side of the test model. When the incidence angle decreases from 0 to -12 degrees, the pressure significantly rises on the windward but changes slightly on the leeward side.

In the vertical plane of symmetry, the pressure distribution is plotted as a function of axial distance for each incidence at the circumferential location of 0 and 180 degrees and shown in Figure 16. Here, we indicate the 0 degrees as the windward side while 180 degrees refers to the leeward side. The surface pressure increases as the incidence reduces from 0 to -12 degrees on the windward side. On the other hand, the pressure drops on the leeward side. The sudden change of the pressure profile is due to the expansion wave located at the corner between the conical surface and the cylindrical portion. At the circumferential location of 0 degrees, the pressure is not constant along the ray on the conical surface, which is also evident in the AA-PSP pressure distribution of Figure 13. This may be explained by the existence of the internal shock wave. At the 180 degrees on the leeward side, a pressure drop is visible around the edge of the model nose and a close-up view is presented as well in Figure 16(b). The effective pressure drop region is increasing which indicates the enlargement of the separation zone due to the overexpansion, which has been shown in the colour schlieren photograph in Figure 13. 


\section{Surface Pressure Mapping from Topview}

To acquire more information about the flow field, the camera was installed on top of the test section to obtain the topview of the pressure distribution. Figure 17 shows the change of the AAPSP intensity ratio distribution along the model surface with the variation of incidences from -12 to 12 degrees with 3 degrees intervals. Unfortunately, the pressure in the vicinity of the model nose after the bow shock is far beyond the AA-PSP a priori calibration range. Direct application of this calibration curve may cause considerable error to the pressure measurement. Due to this reason, the following intensity ratios have not been converted to pressures. However, due to the nature of PSP, the intensity ratio $\mathrm{I}_{\text {ref }} / \mathrm{I}$ is proportional to the pressure ratio $\mathrm{P} / \mathrm{P}_{\text {ref }}$. Therefore, the intensity distribution can still represent the pressure mapping qualitatively. Hence, in the discussion of Figure 17, the term "pressure ratio" is used instead of the intensity ratio when referring to the flow features.

At 0 degrees incidence, in Figure 17, the flow is fully attached to the model surface with the exception of the minor separation region near the nose tip. The separation region is clearly visible in the topview of AA-PSP images, which is previously confirmed in the colour schlieren and sideview of AA-PSP results. The pressure distribution appears much uniform on both the conical and cylindrical surfaces. With increasing the positive incidence, the external flow structure varies leading to the alteration of the surface pressure distribution. The images shown in Figure 17 at positive incidences angles corresponds to the leeward surface of the truncated cone model. The pressure on the conical surface and cylindrical portion decreases with the incidence angles increment. The size of the separation region significantly grows due to the increasing adverse pressure gradient at higher incidence. Complicated pressure patterns occur at a higher angle of attack (12 degrees) which may be because of the viscous effect. On the contrary, the pressure on the conical surface dramatically increases with lowering angle of incidence from 0 to -12. High pressure also appears on the cylindrical portion after the expansion wave, which shows the three-dimensionality of the flow. Meanwhile, the separation region gradually merged at the lower incidences. An "hourglass" shape high pressure region occurs on the windward conical surface. At high angle of attack, the bow shock wave is highly curved and moves close to the model surface on the windward side. Significant crossflow occurs from windward side to leeward side. The surface flow pattern for a thin sharp nose cone model is reported at similar conditions by Bashkin et al. ${ }^{47}$ The crossflow is much apparent from the oil flow results. Due to the lack of detail surface flow visualisation on truncated cone, the reason for the formation of "hourglass" pattern is not fully understood and requires further investigation. 
Some streaks are visible on the leeward side of the model, which are believed to be streamwise vortices. These vortices become visible downstream of the separation region when flow reattaches, especially on the leeward at incidence angles -3 to 12 degrees. The trace of vortex streaks are also visible on the windward side of the model at incidence angle of - 12 degrees from the infrared thermography measurement, presented in Figure 18. The existence of streamwise vortices has also been reported by Matsumura et al. ${ }^{44}$ on the scramjet forebody test in Mach 6 flow. The generation of these vortices is attributed to the combination of freestream noise, leading edge imperfections, and the flow instabilities. Moreover, the vortices can be significantly amplified by the highly unstable separation zone. The separation region exists in the vicinity of the edge of model nose at incidence angles of -3 to 12 degrees, which further amplifies these vortices. Qualitatively, the streamwise vortices are more apparent on the leeward side at angle of attack 12 degrees which has a large separation region. Generally, the spacing between the streaks and the numbers of streaks are different when comparing the leeward side at 12 degrees and windward side at -12 degree. This further proves that it is the flow phenomenon rather then the model imperfection. However, the quantitative analysis of the vortices requires much higher resolution since they are very weak.

\section{Surface Temperature Measurement and PSP Temperature Dependency}

Figure 18 shows the temporal evolution of surface temperature on the windward side of the model surface after flow establishment at -12 degrees incidence. At such angle of attack, the windward side of the model endures the most severe aerodynamic heating. Therefore, the temperature increase should be at its highest.

It can be seen that the entire surface is fairly cold at the beginning of the test and the surface temperature increases during the test. The highest temperature is observed in the vicinity of the edge of the model nose where the bow shock wave is close to the surface. Since the model is manufactured from aluminium, the high thermal conductivity makes the heat spread inside quickly. For most of the region, the temperature rise is restricted to $4{ }^{\circ} \mathrm{C}$ with respect to initial temperature, except a small region near the nose tip where the temperature increase is approximately $5{ }^{\circ} \mathrm{C}$ (see Figure 18). The small surface temperature increase on a metal model in PSP experiments has also been reported by Hirschen et al. ${ }^{22}$

Some streaks are visible on the windward side of the model surface. The spacing between these streaks are different from those observed on the PSP topview. This further proves that these streaks 
are the induced vortices rather than the model imperfection. Three points were chosen along the centreline of the model surface to show the surface temperature history. The first two are located on the conical surface whereas the third one is placed on the cylindrical surface, shown in Figure 18. The temperature history profile at these positions is presented in Figure 19 at the incidence angle of -12 degrees, respectively. As can be seen from the profile, the temperature increase is found to be less than $5{ }^{\circ} \mathrm{C}$ on conical surface and less than $2{ }^{\circ} \mathrm{C}$ on cylindrical surface with respect to the initial temperature.

PSPs also exhibit temperature dependency due to the thermal quenching mechanism. The temperature induced error is attributed to the temperature difference between the test and reference conditions. As aforementioned, the reference image is taken immediately after each test when the model temperature is close to the test condition. Since the PSP images were averaged, the time averaged temperature rise is calculated corresponding to the same time duration with respective to the reference temperature. The temperature rise is taken along the centreline on the windward side and plotted in Figure 20. As can be seen from the profile, the temperature difference between the averaged test image and reference condition is $\pm 2{ }^{\circ} \mathrm{C}$. On the cylindrical portion, the temperature in the test duration is even lower than the reference condition.

Sakaue et al. ${ }^{45}$ has reported a $-1.38 \% /{ }^{\circ} \mathrm{C}$ temperature dependency for a AA-PSP with a recipe similar to that used in the present investigation. The temperature sensitivity of the present AA-PSP substrate has been measured by Quinn et al. ${ }^{46}$ and a $-0.64 \% /{ }^{\circ} \mathrm{C}$ was calculated. The temperature dependency is equivalent to $117.7 \mathrm{~Pa} /{ }^{\circ} \mathrm{C}$ according to the calibration curve in Figure12. The maximum temperature difference between the test and reference condition is around $\pm 2{ }^{\circ} \mathrm{C}$ on the windward side for the most critical angle of attack, -12 degree. It leads to a pressure inaccuracy of $\pm 240 \mathrm{~Pa}$ and $\mathrm{a} \pm 2.5 \%$ uncertainty of local pressure.

Nakakita et al. ${ }^{33}$ has reported a temperature dependency of $0.5 \% /{ }^{\circ} \mathrm{C}$ for a similar AA-PSP recipe, which corresponds to $150 \mathrm{~Pa} /{ }^{\circ} \mathrm{C}$ from the calibration curve. Only several Kelvin surface temperature rise is estimated on the metal model in shock tunnel test due to the short duration, high thermal conductivity and heat mass of the model. The temperature effect was neglected and uncorrected AA-PSP measurement shows a nice agreement with the Kulite pressure transducer reading on twodimensional compression/expansion ramp and three dimensional wing-body model. ${ }^{33,34}$ The standard deviation of the uncorrected AA-PSP measurement and the Kulite transducer reading on twodimensional model is about $2.6 \%$. The temperature effect for the latter model is studied by changing the test gas from air to nitrogen since PSP is insensitive to nitrogen. It is found that the temperature 
effect is less than $4 \%$ except the model nose and shock impingement region. In a shock tunnel test by Sakaue et al. ${ }^{27}$, pressure measured from the uncorrected AA-PSP on hemisphere and scramjet inlet model shows pressure uncertainties of 4-6 percent with comparison with CFD results in shock tunnel test. ${ }^{26}$ Gregory et al. ${ }^{26}$ concluded that several Kelvin of surface temperature rise in the shock tunnel test is almost negligible for thin PSP coating because of the small heat mass. Although the present test was conducted in a blow-down wind tunnel, the surface temperature increase restricts to several Kelvin from the infrared thermography measurement results. The temperature effect is minimal and detail uncertainty has reported as aforementioned.

\section{CONCLUSIONS}

Hypersonic flow passing a semi-apex angle of 15 degrees truncated cone was experimentally studied in Mach 5 flow with a unit Reynolds number of $13.5 \times 10^{6} \mathrm{~m}^{-1}$. The model incidence varied from -12 to 12 degrees with 3 degrees intervals relative to the freestream direction. For better understanding of the complicated flow feature, multiple measurement techniques including colour schlieren photography, oil dot flow visualisation, and AA-PSP techniques were utilised to study the flow patterns and acquire surface pressure distribution. Colour schlieren was applied to identify the external flow pattern while oil dot flow technique indicated the surface flow patterns. AA-PSP provided the global pressure distribution on the truncated cone surface at various incidence angles.

In the presence of hypersonic flow, a highly curved bow shock wave was created around the truncated cone. The shape of the bow shock wave changes with varying of incidence angle, which further leads to the alternation of pressure distribution on the model surface significantly. A separation region formed near the edge between the flat model nose and conical surface. The size of separation region grew on the leeward side but was reduced on the windward side with changing of incidence angles, revealed both by the colour schlieren photography and oil flow method. An internal shock wave was found originating from the edge of model nose as well. The reason for the formation of such separation and internal shock wave is believed to be due to the overexpansion at the corner between the flat model nose and conical surface. The oil dot technique captures the transverse flow pattern from the low pressure leeward side to the high pressure windward side.

The feasibility and potential application of AA-PSP technique was demonstrated on the truncated cone model. With the help of the high resolution of the pressure mapping obtained by AA-PSP, complicated flow patterns were captured by the AA-PSP. The results obtained from AA-PSP are 
correlating well with the visualisation by the colour schlieren and oil flow methods. The pressure apparently increases as the angle of incidence reduces from 0 to -12 degrees on the windward side, but dramatically drops on leeward side. In the circumferential direction, the pressure is found to monotonically decrease with the circumferential angle as the incidence is lowered. The complicated "hourglass" shape high pressure pattern was revealed by the AA-PSP technique. However, the reason for generation of such flow pattern is complicated and needs further investigation.

The formation of separation region on the leeward is further confirmed from the topview visualisation results. The separation region enlarges when the incidence angle increases. However, this separation region gradually vanishes on the windward side. The trace of vortices streaks were visualised after flow reattaches on the leeward side. The generation of vortices streaks is believed to be induced by the nose edge and further amplified by the unstable separation region.

Systematic studies of truncated cone flows are underway to examine the effect of truncation ratio, apex-angle, and Mach numbers.

\section{Acknowledgments}

The authors would like to thanks the technical staff at University of Manchester for their help and assistance. The scholarship provided by the UK-China Scholarships for Excellence programme for the first author is highly appreciated. The support of the EPSRC Engineering Instrument Pool for the loan of the spectrometer and laser surface profiler are greatly acknowledged as well.

1 Giese, J.H., , "Interferometric Studies of Supersonic Flows about Truncated Cones," Journal of Applied Physics 24, pp. 1389-1396, 1953.

${ }^{2}$ Lin, T.C., Rubin, S.G., "Viscous flow over a cone at moderate incidence. Part 2. Supersonic boundary layer," Journal of Fluid Mechanics 59, pp. 593-620, 1973.

3 Fletcher, C., Holt, M., "Supersonic viscous flow over cones at large angles of attack," Journal of Fluid Mechanics 74, pp. 561-591, 1976.

4 Nebbeling, C., Bannink, W.J., "Experimental investigation of the supersonic flow past a slender cone at high incidence," Experimental Thermal and Fluid Science 87, pp. 475-496, 1978. 
5 Marconi,F., "Complex shock patterns and vortices in inviscid supersonic flows," Computers $\mathcal{E}$ Fluids 17, pp. 151-163, 1989.

6 Rainbird, W.J., "Turbulent boundary-layer growth and separation on a yawed cone," AIAA Journal 6 , pp. 2410-2416, 1968.

7 Adams, J. C. JR, "Three-dimensional compressible turbulent boundary layer on a sharp cone at incidence in supersonic flow," International Journal of Heat and Mass Transfer 17, pp. 581-593, 1974.

8 Lin, T.C., Grabowski, W.R., Yelmgren, K.E., "The search for optimum configurations for re-entry vehicles," Journal of Spacecraft and Rockets 21, pp. 142-149, 1984.

9 Bivolaru, D., Kuo, S.P., "Observation of supersonic shock wave mitigation by a plasma aero-spike," Physics of Plasma 9, pp. 721-723, 2002.

10 Kuo, S.P., "Plasma mitigation of shock wave: experiments and theory," Shock Waves 17, pp. 225-239, 2007.

11 Sakai, T., "Supersonic drag performance of truncated cones with repetitive energy depositions," International Journal of Aerospace Innovation 1, pp. 31-34, 2009.

12 Erdem, E., Yang, L., Kontis, K., "Drag reduction by energy deposition in hypersonic flows," 16th AIAA/DLR/DGLR International Space Planes and Hypersonic Systems and Technologies Conference, Germany, AIAA-2009-7347, 2009.

13 Borzov, V.Y., Rybka, I.V., Yur'ev, A.S., "Effect of local energy supply to a hypersonic flow on the drag of bodies with different nose bluntness," Journal of Engineering Physics and Thermophysics 67, pp. 997-1002, 1994.

14 Brodetsky, M.D., Shevchenko, A.M., "Experimental study of supersonic flow around truncated cones at incidence," Journal of Applied Mechanics and Technical Physics 44, pp. 640-647, 2003.

15 Kontis, K., "A review of some current research on pressure sensitive paint and thermographic phosphor techniques," Aeronautical Journal 111, pp. 495-508, 2007.

16 Liu, T., Campbell, B.T., Sullivan, J.P., "Fluorescent paint for measurement of heat transfer in shock turbulent boundary layer interaction," Experimental Thermal and Fluid Science 10, pp. 101-112, 1995.

17 Dowgwillo, R.M., Morris, M.J., Donovan, J.F., Benne, M.E., "Pressure sensitive paint in transonic wind-tunnel testing of the F-15," Journal of Aircraft 33, pp. 109-116, 1996.

18 Hubner, J.P., Carroll, B.F., Schanze, K.S., Ji, H.F., "Pressure-sensitive paint measurements in a shock tube," Experiments in Fluids 28, pp. 21-28, 2001.

19 Watkins, A.N., Oglesby, D.M., Leighty, B.D., Jordan, J.D., "Low Speed Pressure Sensitive Paint 
Measurements-Requirements and Applications," Proceedings of the International Instrumentation Symposium 47, pp. 203-214, 2001.

20 Hubner, J.P., Carroll, B.F., Schanze, K.S., Ji, H.F., Holden, M.S., "Temperature- and pressure-sensitive paint measurements in short-duration hypersonic flow," AIAA Journal 39, pp. 654-659, 2001.

21 Kurita, M., Nakakita, K., Mitsuo, K., Watanabe, S., "Temperature correction of pressure-sensitive paint for industrial wind tunnel testing," Journal of Aircraft 43, pp. 1499-1505, 2006.

${ }^{22}$ Hirschen, C.,Gülhan, A.,Beck, W.H., Henne, U., "Experimental Study of a Scramjet Nozzle Flow Using the Pressure-Sensitive-Paint Method," Journal of propulsion and power 24, pp. 662-672, 2008.

23 Zare-Behtash, H., Gongora-Orozco, N., Kontis, K., Holder, S.J., "Application of novel pressure-sensitive paint formulations for the surface flow mapping of high-speed jets," Experimental Thermal and Fluid Science 33, pp. 852-864, 2009.

24 Zare-Behtash, H., Gongora-Orozco, N., Kontis, K., "PSP visualization studies on a convergent nozzle with an ejector system," Journal of Visualisation 12, pp. 233-240, 2009.

25 Gongora-Orozco, N., Zare-Behtash, H., Kontis, K., "Global unsteady pressure-sensitive paint measurements of a moving shock wave using thin-layer chromatography," Measurement 43, pp. 152-155, 2010.

26 Gregory, J.W., Asai, K., Kameda, M., Liu, T., Sullivan, J.P., "A review of pressure-sensitive paint for high-speed and unsteady aerodynamics," Proceedings of the Institute of Mechanical Engineers, Part G: Journal of Aerospace Engineering 222, pp. 249-290, 2008.

27 Sakaue, H., Matsumura, S., Schneider, S.P., Sullivan, J.P., "Anodized Aluminum Pressure Sensitive Paint for Short Duration Testing," 22nd AIAA Aerodynamic Measurement Technology and Ground Testing Conference, Missouri, AIAA-2002-2908, 2002.

28 Sakaue, H., Sullivan, J.P., "Time response of anodized aluminum pressure-sensitive paint," AIAA Journal 39, pp. 1944-1949, 2001.

29 Kameda, M., Tezuka, N., Hangai, T., Asai, K., Nakakita, K., Amao, Y., "Adsorptive pressure-sensitive coatings on porous anodized aluminium," Measurement Science and Technology 15, pp. 489-500, 2004.

30 Kameda, M., Tabei, T., Nakakita, K., Sakaue, H., Asai, K., "Image measurements of unsteady pressure fluctuation by a pressure-sensitive coating on porous anodized aluminium," Measurement Science and Technology 16, pp. 2517-2524, 2005.

31 Sakamura, Y., Matsumoto, M., Suzuki, T., "High frame-rate imaging of surface pressure distribution using a porous pressure-sensitive paint," Measurement Science and Technology 16, pp. 759-765, 2005.

32 Sakaue, H., "Porous pressure-sensitive paint for characterizing unsteady flowfields," AIAA Journal 40, 
pp. 1094-1098, 2002.

33 Nakakita, K., Yamazaki, T., Asai, K., Teduka,N., Fuji, A., Kameda, M. "Pressure Sensitive Paint Measurement in a Hypersonic Shock Tunnel," 21st AIAA Aerodynamic Measurement Technology and Ground Testing Conference, Denver, AIAA-2000-2523, 2000.

34 Nakakita, K., Asai, K., "Pressure-Sensitive Paint Application to a Wing-Body Model in a Hypersonic Shock Tunnel," 22nd AIAA Aerodynamic Measurement Technology and Ground Testing Conference, Missouri, AIAA-2002-2911, 2002.

35 Erdem, E., Kontis, K., "Numerical and experimental investigation of transverse injection flows," Shock Waves, 20, pp. 103-118, 2010.

36 Sakaue, H., "Luminohpore application method of anodized aluminium pressure sensitive paint as a fast responding global pressure sensor," Review of Scientific Instruments 76, pp. 1-6, 2005.

37 Yang, L., Zare-Behtash, H., Erdem, E., Kontis, K., "Application of AA-PSP to Hypersonic Flows: The Double Ramp Model," Sensors and Actuators B: Chemical, 161, pp. 100-107, 2012.

38 Yang, L., Zare-Behtash, H., Erdem, E., Kontis, K., "Investigation of the Double Ramp in Hypersonic Flow Using Luminescent Measurement Systems," Experimental Thermal and Fluid Science, In press.

39 Gongora-Orozco, N., Zare-Behtash, H., Kontis, K., "Effects of filters on the pressure-sensitive paints performance and characteristics," Measurement Science and Technology 20, 077004, 2009.

40 Kontis, K., Qin, N., Stollery, J.L., Edwards, J.A., "Hypersonic performance of a lifting elliptic cone with and without strakes," Journal of Spacecraft and Rockets 37, pp. 21-27, 2000.

41 Kontis, K., "Flare-Control Effectiveness at Hypersonic Speeds," Transactions of the Japan Society for Aeronautical and Space Sciences 47, pp. 116-123, 2004.

42 Kontis, K., "Flow control effectiveness of jets,strakes,and flares at hypersonic speeds," Proceedings of the Institution of Mechanical Engineers Part G Journal of Aerospace Engineering 222, pp. 585-603, 2008.

43 Squire, L.C., "The motion of a thin oil sheet under the boundary layer on a body," AGARDograph AGARD-AG-70, 1962.

44 Matsumura, S., Schneider, S.P., Berry, S.A., "Streamwise Vortex Instability and Transition on the Hyper-2000 Scramjet Forebody," Journal of Spacecraft and Rockets 42, pp. 78-89, 2005.

45 Sakaue, H., Ishii, K., "Optimization of anodized-aluminum pressure-sensitive paint by controlling luminophore concentration," Sensors 10, pp. 6836-6847, 2008.

46 Quinn, M.K., Yang, L., Kontis, K., "Pressure-Sensitive Paint: Effect of Substrate," Sensors 11, pp. 
11649-11663, 2011.

47 Bashkin, V.A., Egorov, I.V., Pafnut'ev, V.V., "Aerodynamic Heating of a Thin Sharp-Nose Circular Cone in Supersonic Flow," High Temperature 43, pp. 733-745, 2005.

TABLE I: Experimental conditions of AA-PSP on truncated cone model

Total pressure $[\mathrm{kPa}]$ $645.9 \pm 0.7 \%$

Total temperature $[\mathrm{K}]$ $372.3 \pm 1.7 \%$

Mach number $5.0 \pm 0.4 \%$

Free stream pressure $[\mathrm{kPa}]$ $1.22 \pm 2.4 \%$

Free stream temperature $[\mathrm{K}]$ $62.5 \pm 1.7 \%$

Incidences -12 to 12 with $3 \pm 0.2$ degrees interval 


\section{List of Figures}

1 Schematic diagram of the hypersonic wind tunnel. . . . . . . . . . . . . . . . 21

2 Typical total pressure, pitot pressure, and temperature signal. . . . . . . . . . . . 21

3 Truncated cone model with AA-PSP coating and dimensions (all dimensions in mm). 21

4 SEM image of anodized aluminium surface $^{37} \ldots \ldots \ldots \ldots \ldots \ldots$. . . . . . . . . 22

5 Schematic of schlieren system. . . . . . . . . . . . . . . . . . . . 22

6 Oil flow setup with oil streaks on the model after run. . . . . . . . . . . . . . . . 23

7 Optical setup of AA-PSP experiment. . . . . . . . . . . . . . . . . 23

8 Spectral analysis of AA-PSP emission with LED excitation. . . . . . . . . . . . 24

9 Colour schlieren of hypersonic flow around truncated cone at -12 degrees incidence. . 24

10 Fluorescent oil flow on the truncated cone at various incidences. . . . . . . . . . . . . 25

11 A priori calibration, variation of intensity ratio $\mathrm{I}_{\mathrm{ref}} / \mathrm{I}$ with increasing pressure ratio $\mathrm{P} / \mathrm{P}_{\text {ref }}$, reference pressure $2.39 \mathrm{kPa} . \ldots \ldots \ldots \ldots \ldots$

12 A priori calibration curve, reference pressure $2.39 \mathrm{kPa} \ldots \ldots \ldots$. . . . . . . 26

13 Comparison of flow structures visualised by colour schlieren and AA-PSP. . . . . . . . 27

14 Schematic of the circumferential and streamwise coordinates. . . . . . . . . . . . . 28

15 Pressure distribution along the circumferential coordinate, (a) location 1, (b) location 2, (c) location 3, (d) location 4 (see Figure 14 for the locations). . . . . . . . . . . . . 28

16 Pressure distribution along a ray in the vertical plane of symmetry at (a) 0 degrees, (b) 180 degrees (see Figure 14 for coordinates). . . . . . . . . . . . . . . . 29

17 Intensity ratio of truncated cone at different angles of attack. . . . . . . . . . . . 30

18 Temporal evolution of surface temperature distribution on windward side, AoA -12

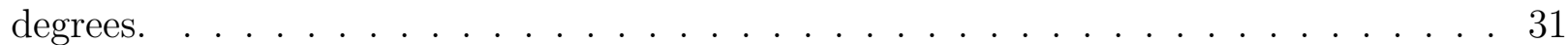

19 Surface temperature history on windward side, AoA -12 degrees (see Figure 18 for

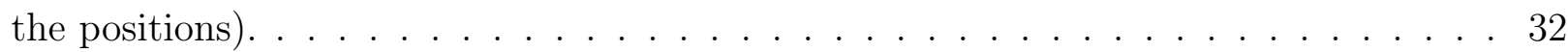

20 Averaged temperature difference with respective to reference temperature, windward side at AoA -12 degrees . . . . . . . . . . . . . . . . . . 32 


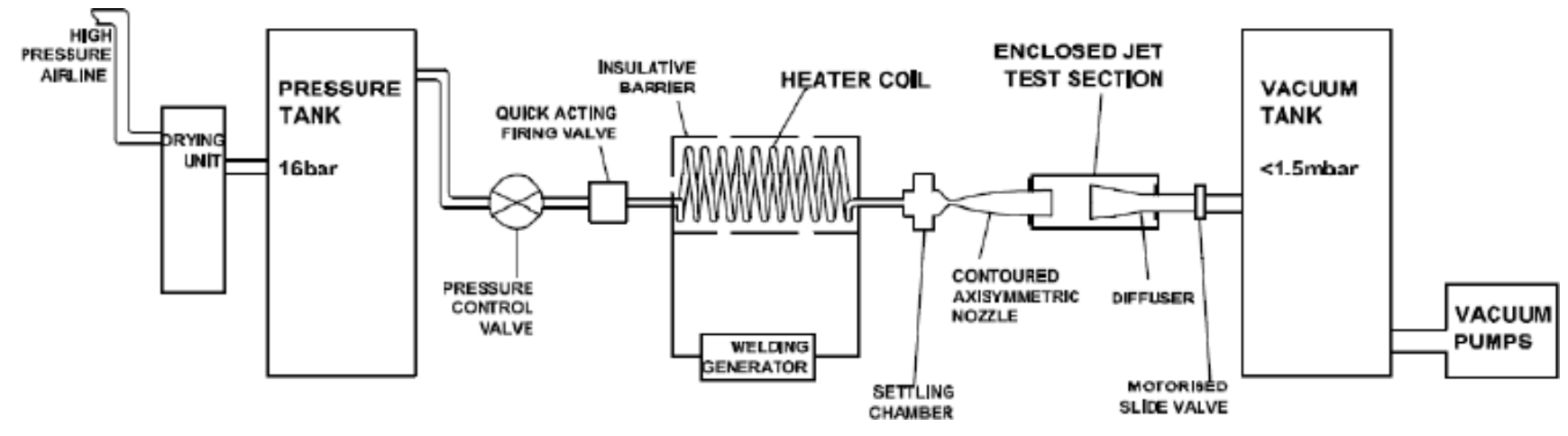

FIG. 1: Schematic diagram of the hypersonic wind tunnel.

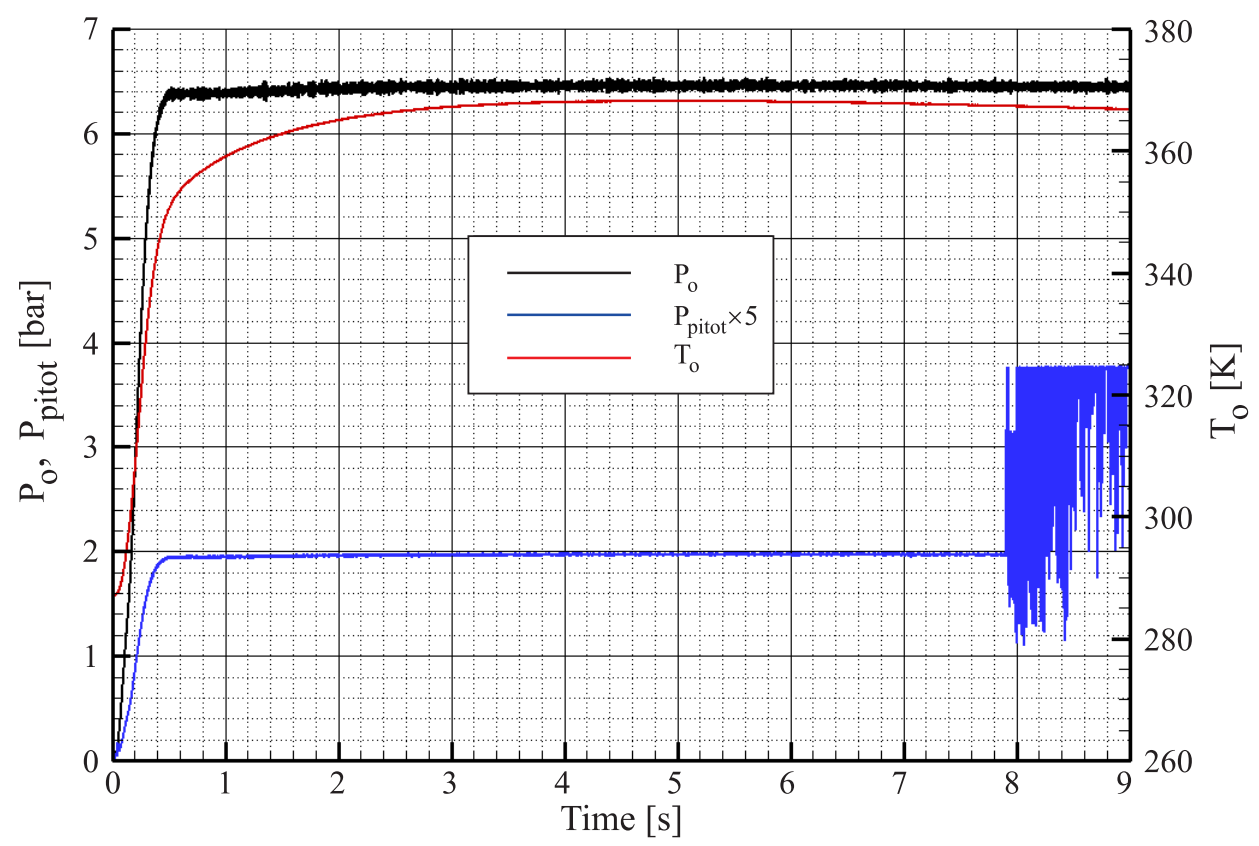

FIG. 2: Typical total pressure, pitot pressure, and temperature signal.

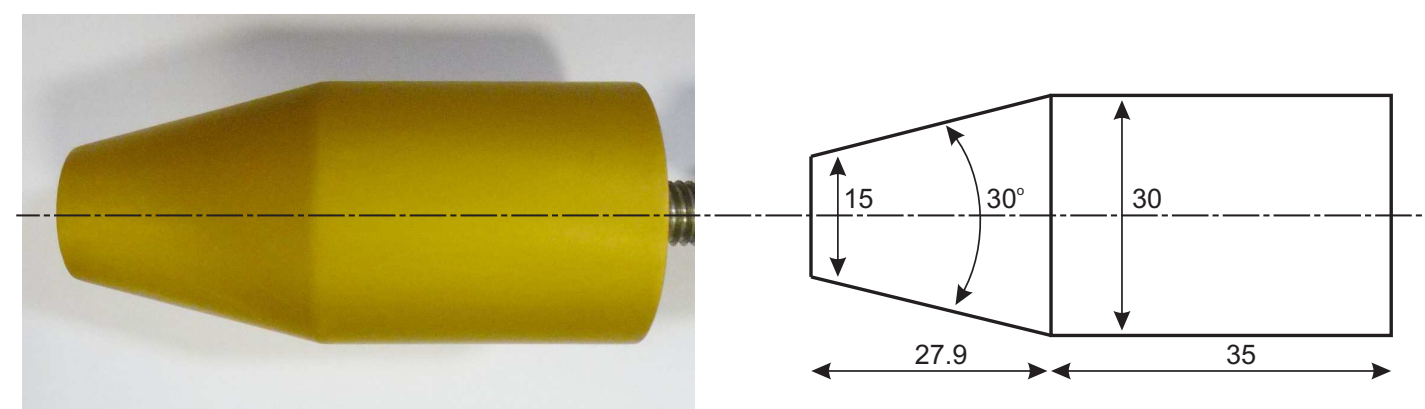

FIG. 3: Truncated cone model with AA-PSP coating and dimensions (all dimensions in mm). 


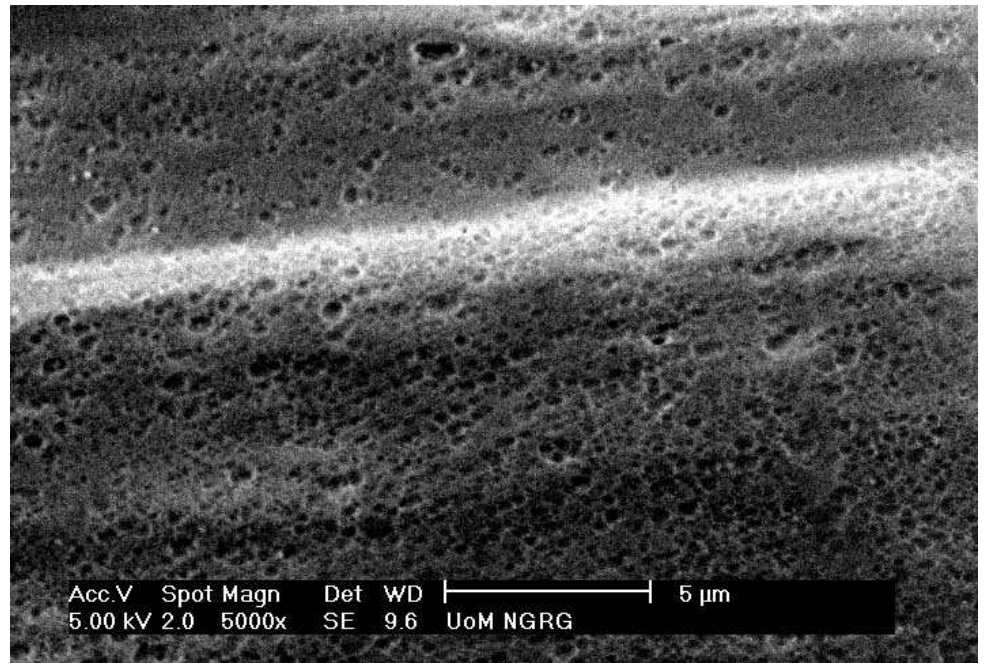

FIG. 4: SEM image of anodized aluminium surface ${ }^{37}$.

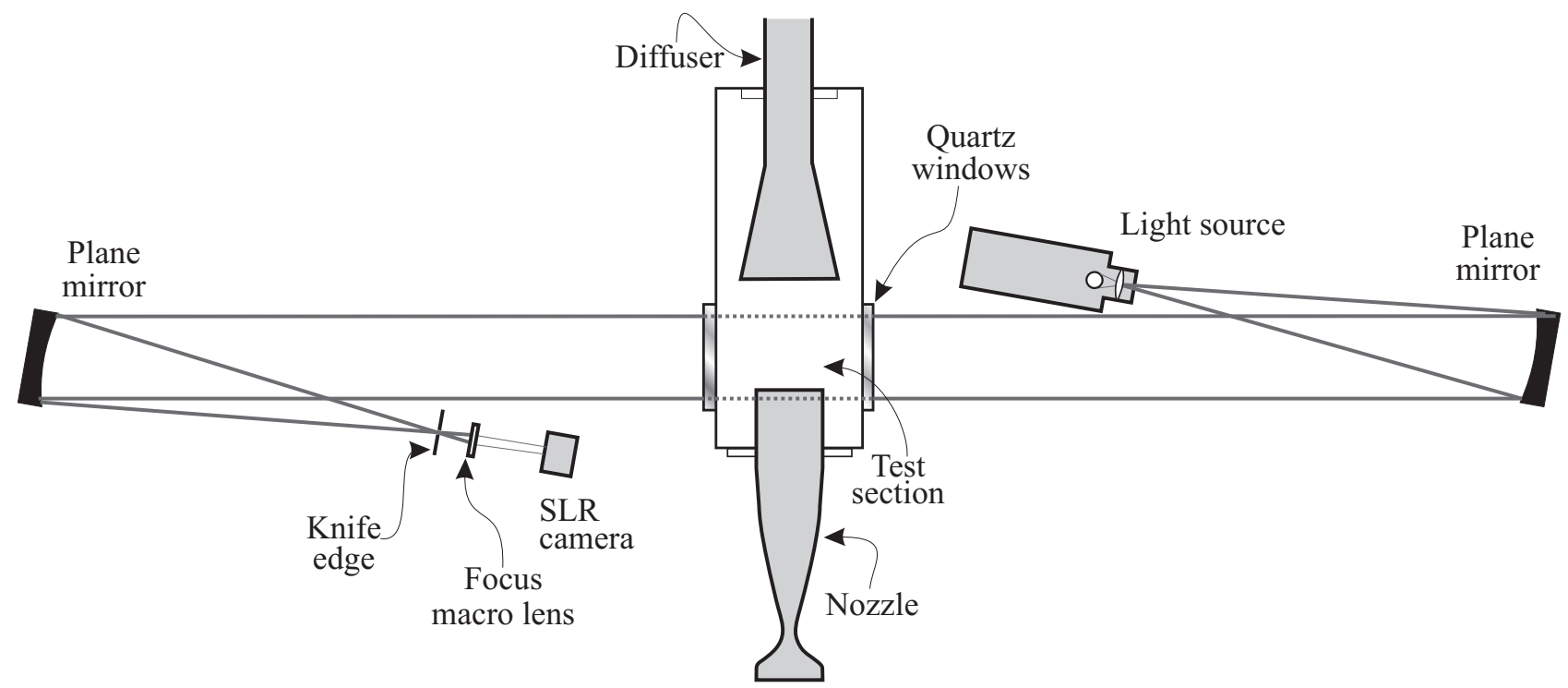

FIG. 5: Schematic of schlieren system. 


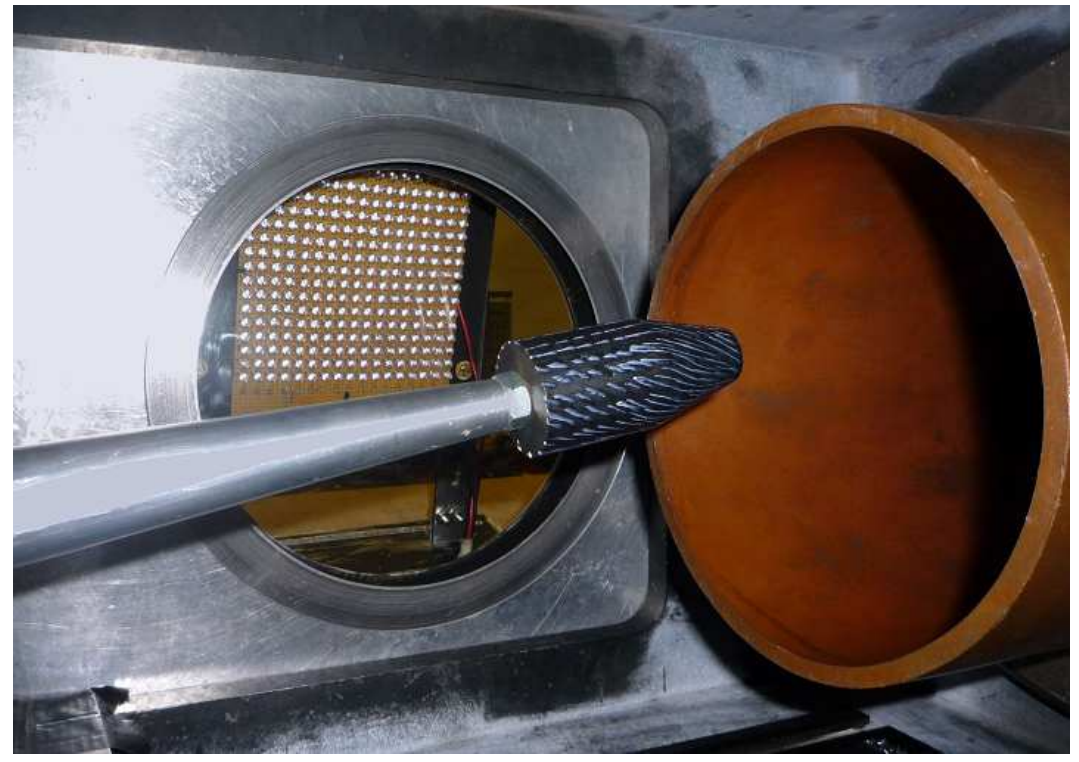

FIG. 6: Oil flow setup with oil streaks on the model after run.

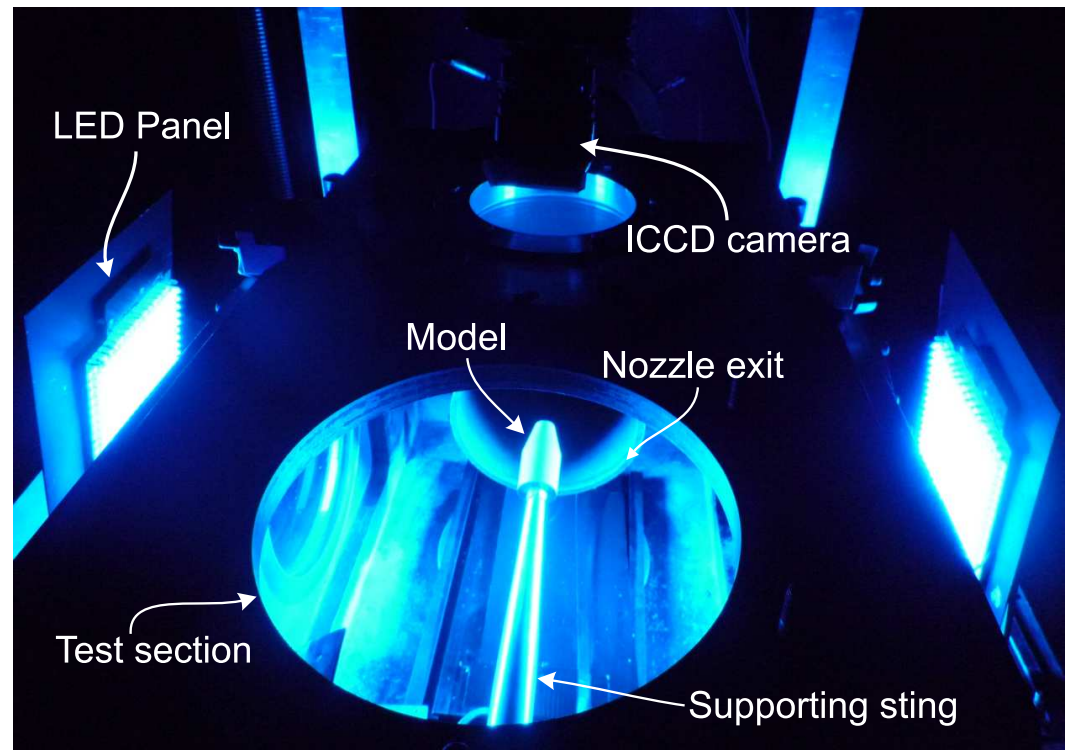

FIG. 7: Optical setup of AA-PSP experiment. 


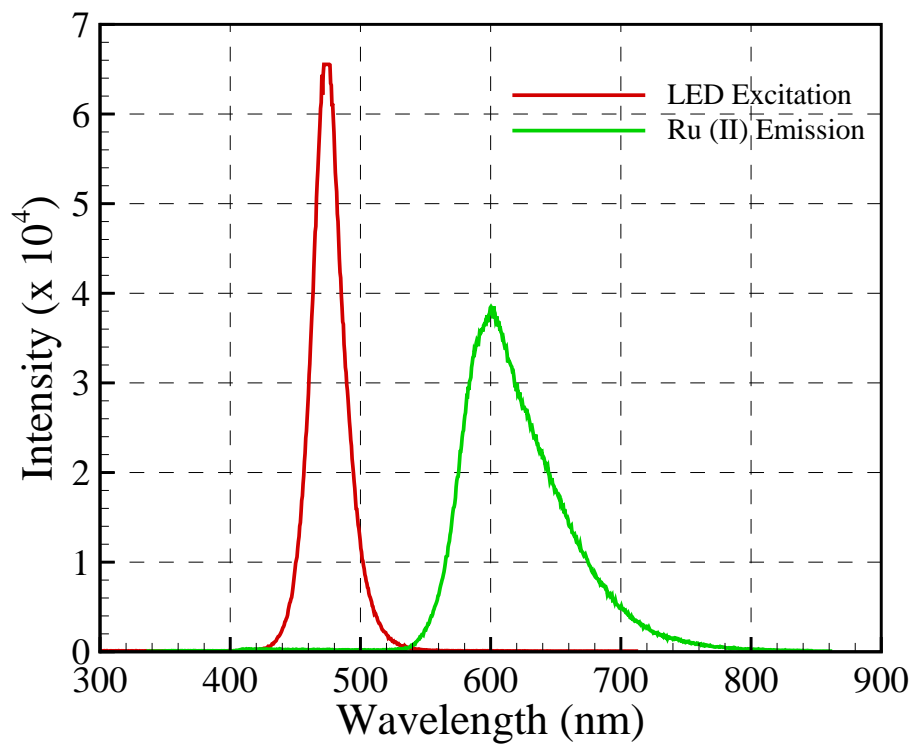

FIG. 8: Spectral analysis of AA-PSP emission with LED excitation.

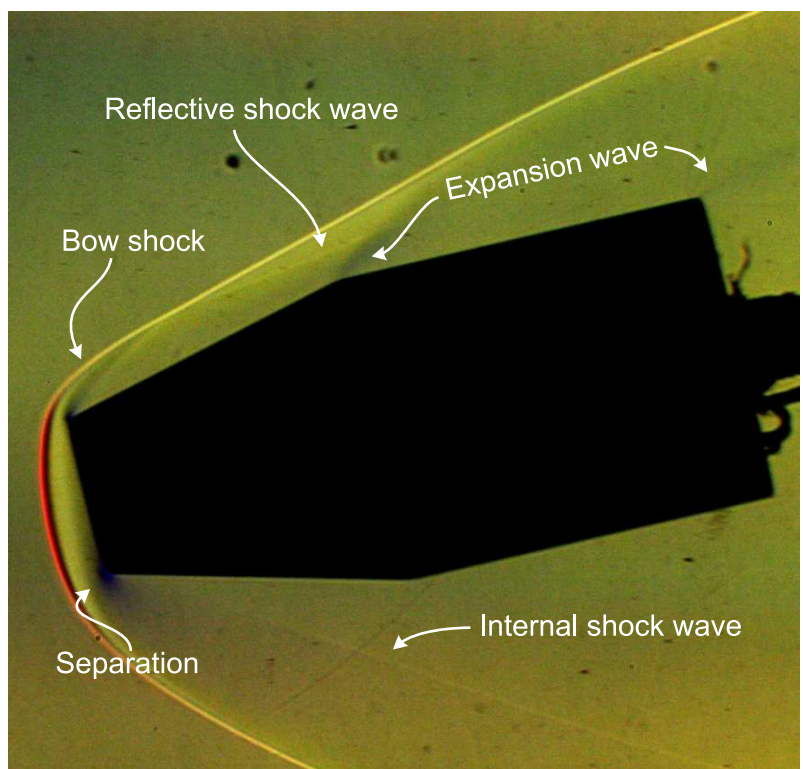

FIG. 9: Colour schlieren of hypersonic flow around truncated cone at -12 degrees incidence. 

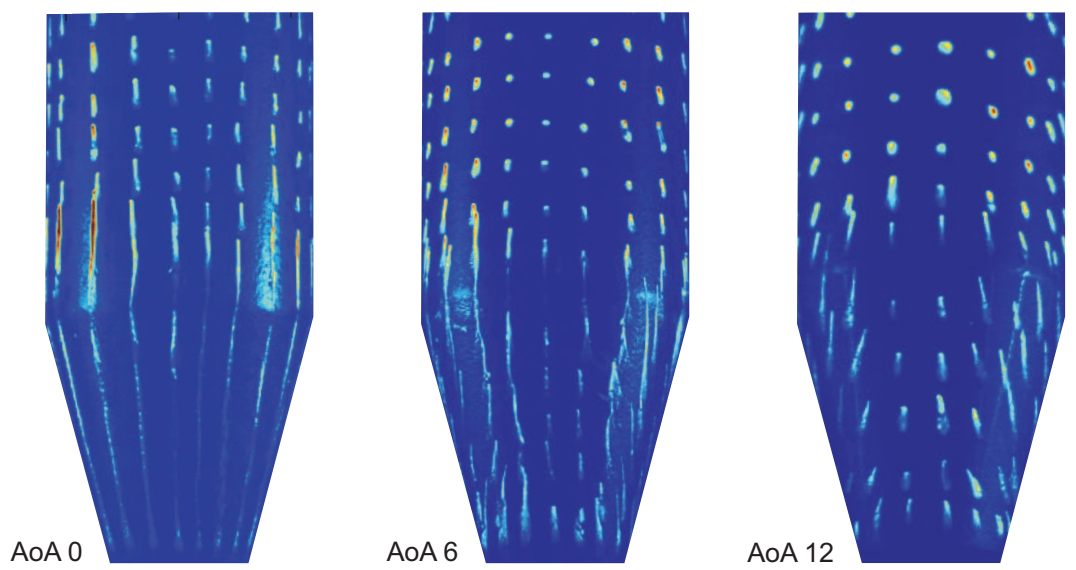

FIG. 10: Fluorescent oil flow on the truncated cone at various incidences.

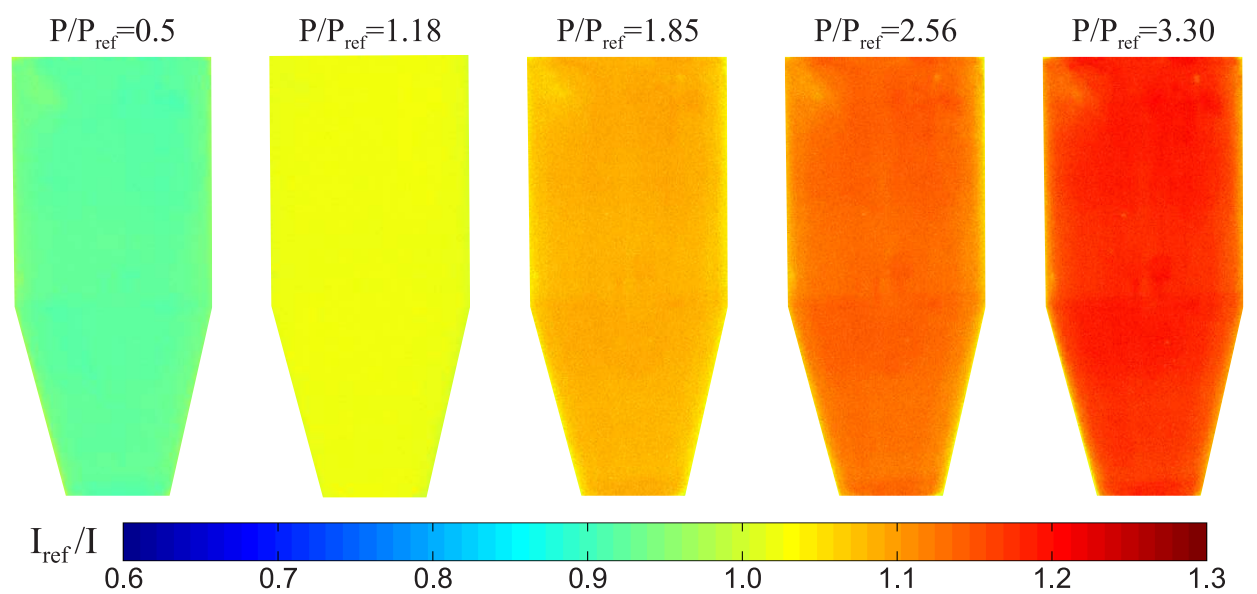

FIG. 11: A priori calibration, variation of intensity ratio $\mathrm{I}_{\mathrm{ref}} / \mathrm{I}$ with increasing pressure ratio $\mathrm{P} / \mathrm{P}_{\text {ref }}$, reference pressure $2.39 \mathrm{kPa}$. 


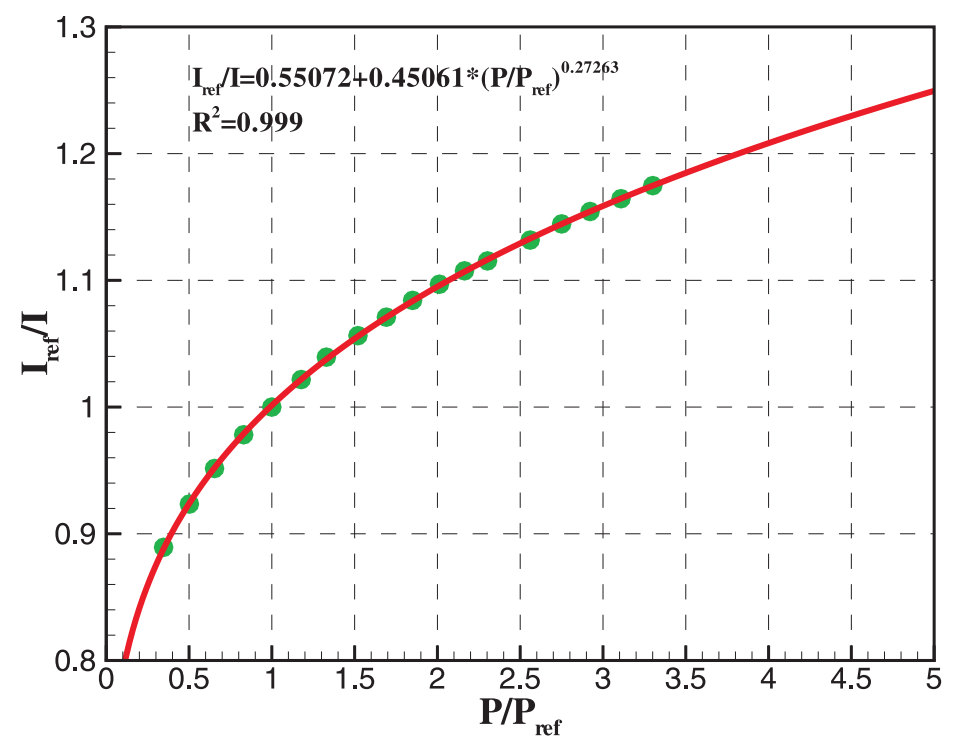

FIG. 12: A priori calibration curve, reference pressure $2.39 \mathrm{kPa}$. 

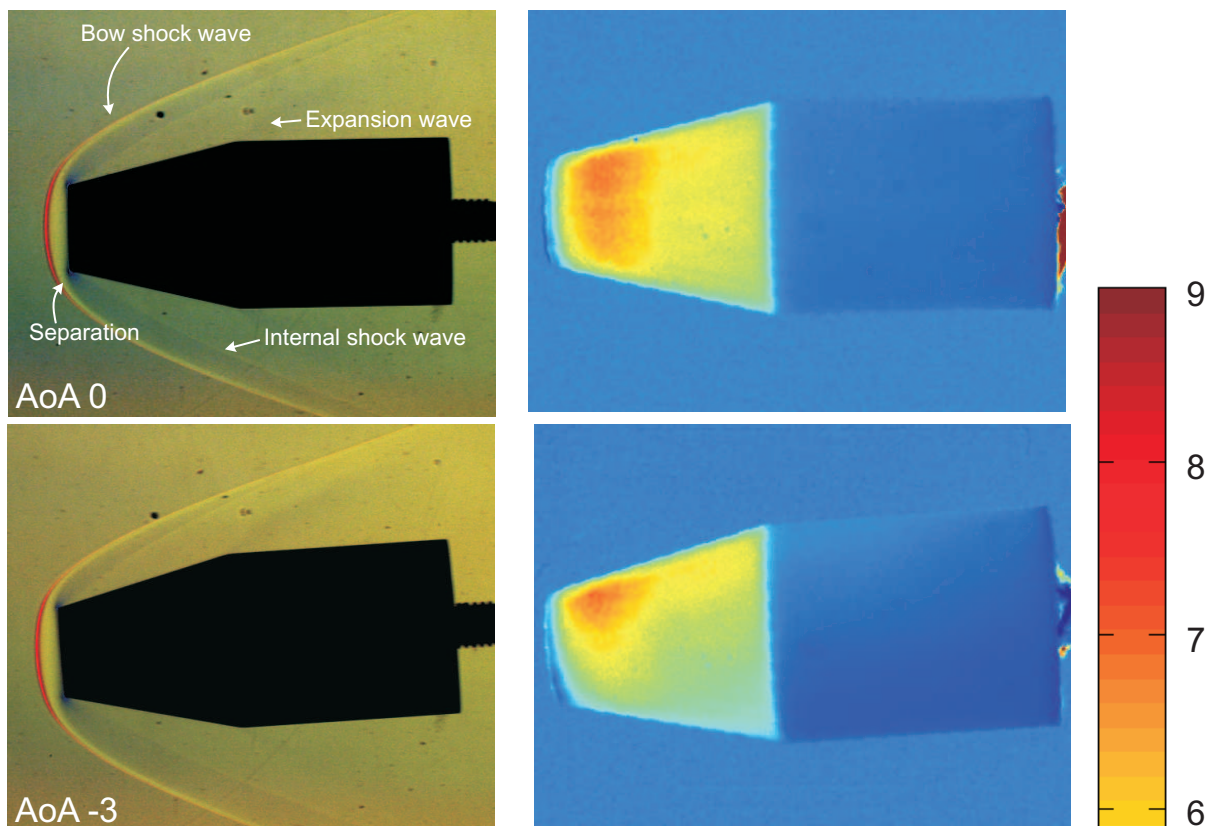

AoA -3

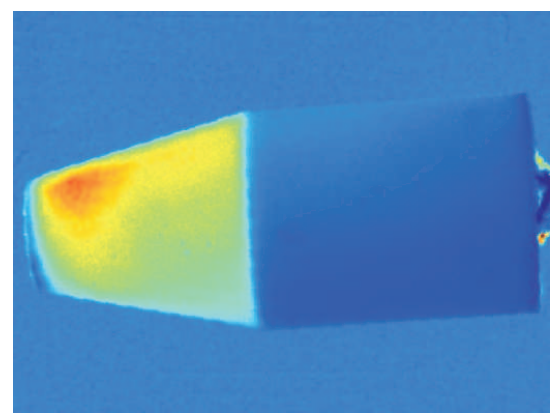

8
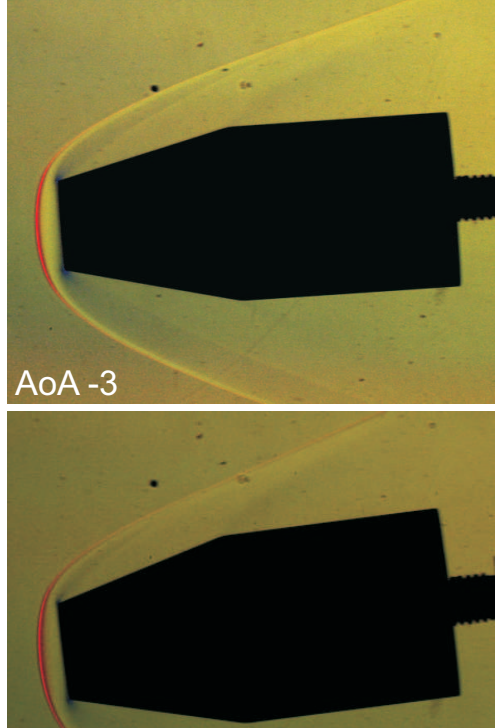

AoA - 6
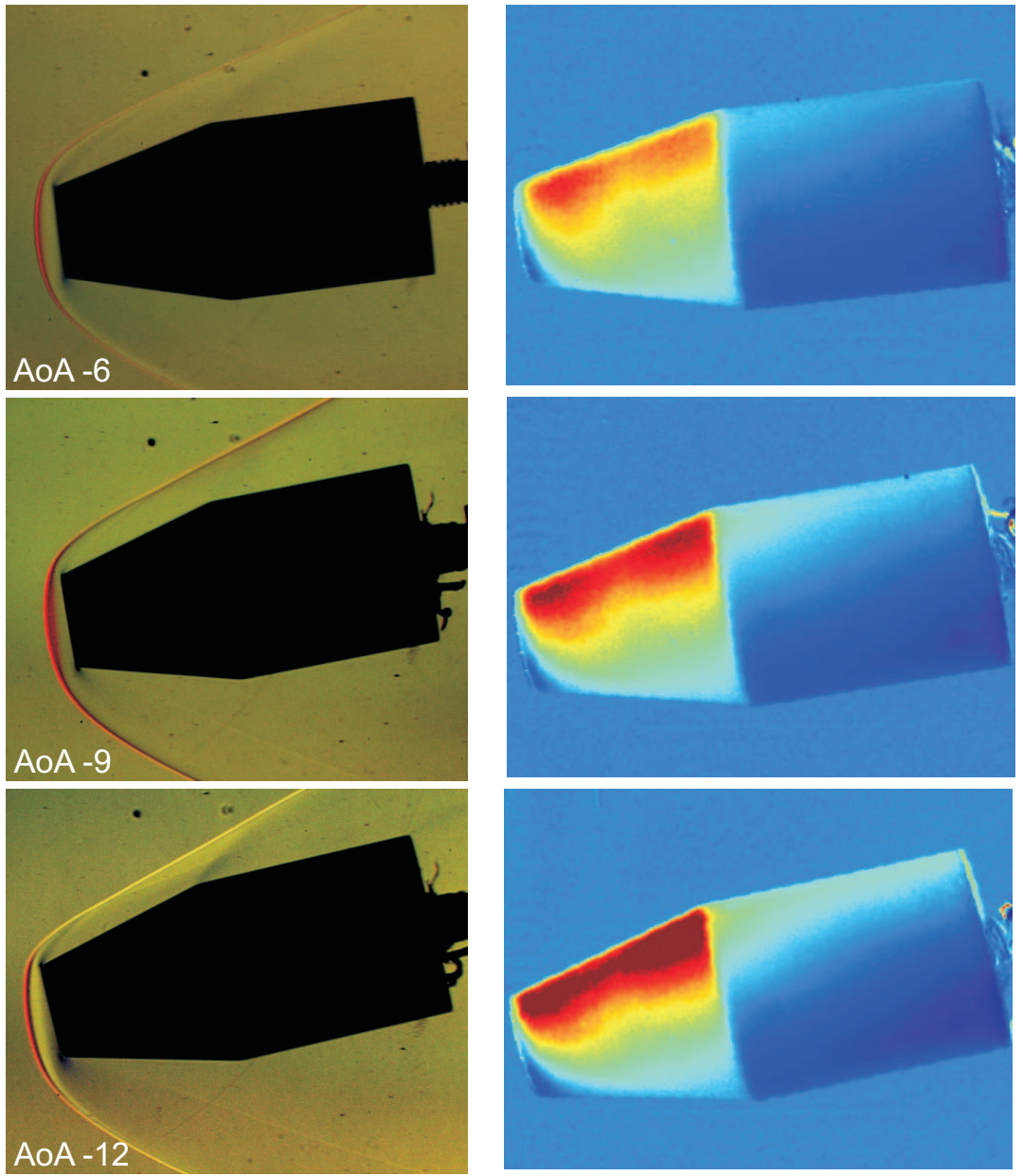

FIG. 13: Comparison of flow structures visualised by colour schlieren and AA-PSP. 


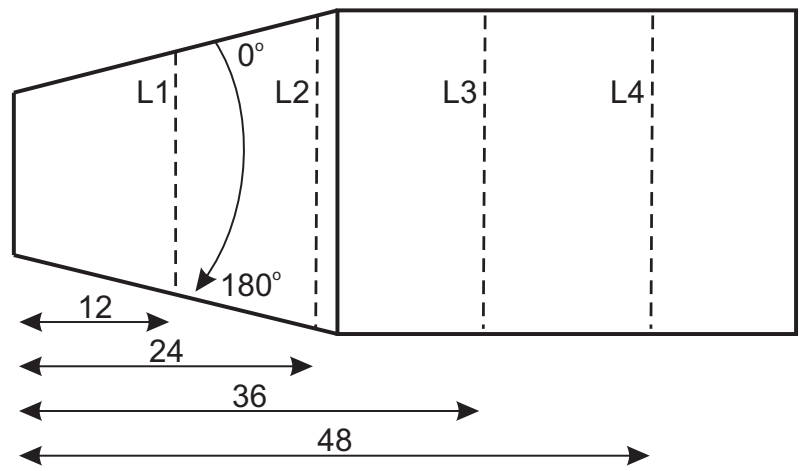

FIG. 14: Schematic of the circumferential and streamwise coordinates.

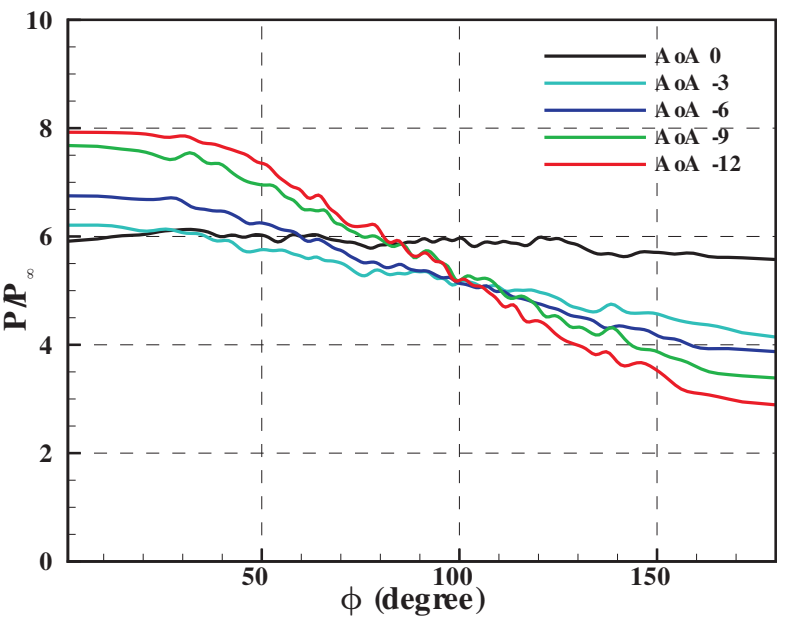

(a)

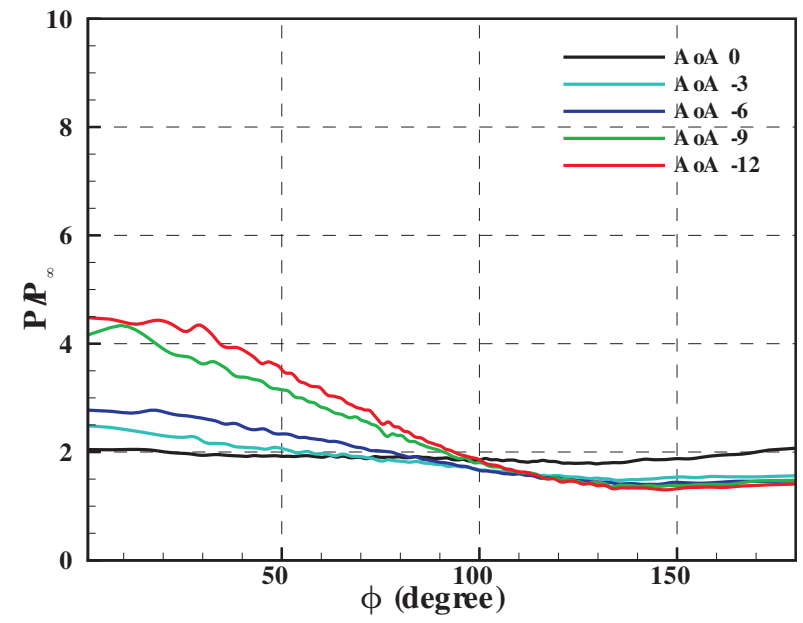

(c)

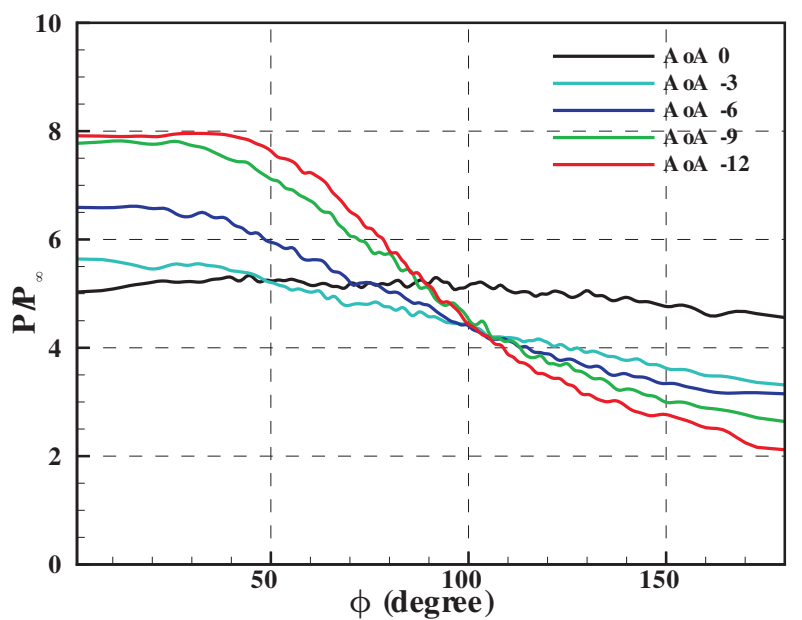

(b)

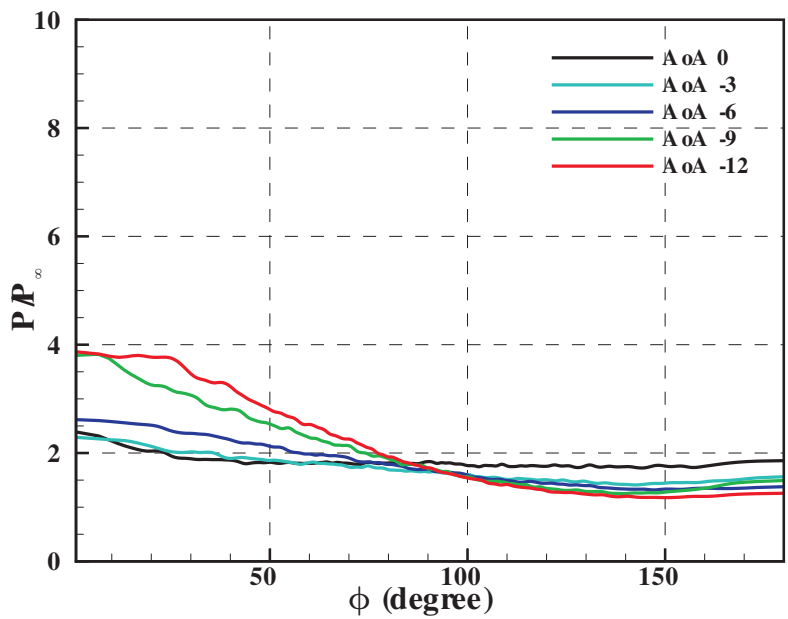

(d)

FIG. 15: Pressure distribution along the circumferential coordinate, (a) location 1, (b) location 2, (c) location 3, (d) location 4 (see Figure 14 for the locations). 

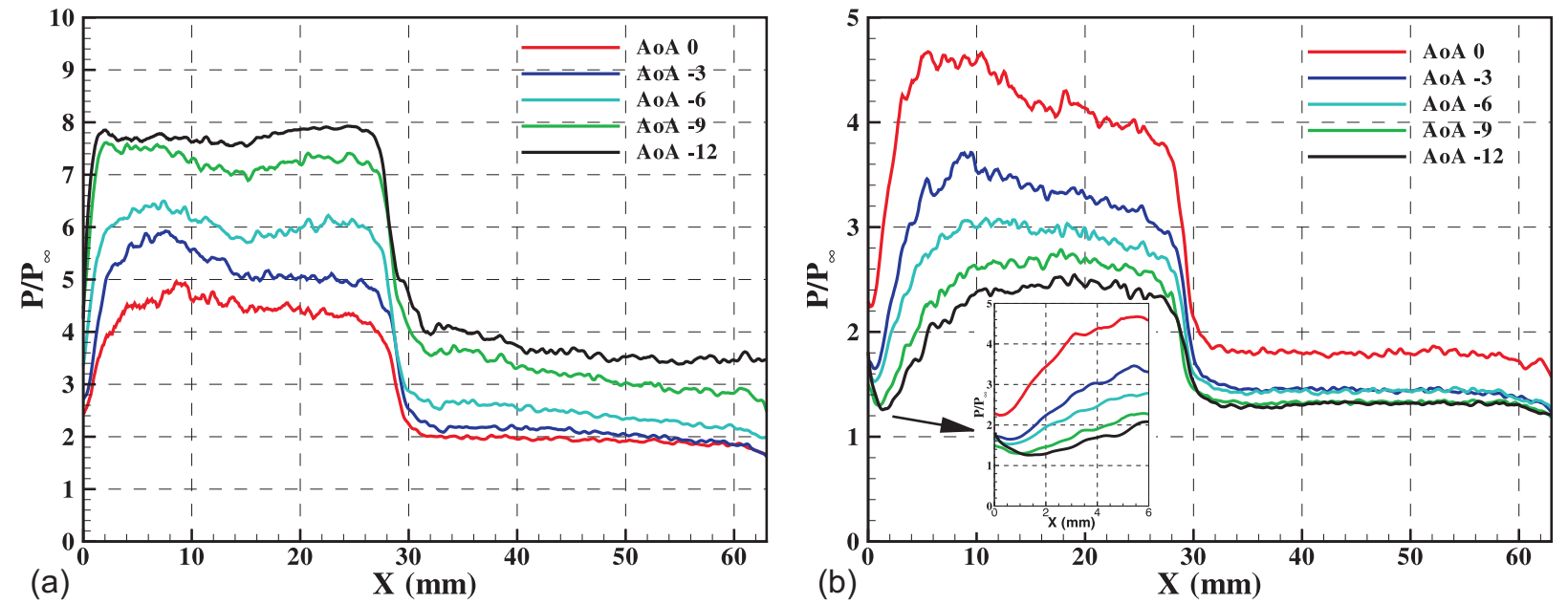

FIG. 16: Pressure distribution along a ray in the vertical plane of symmetry at (a) 0 degrees, (b) 180 degrees (see Figure 14 for coordinates). 


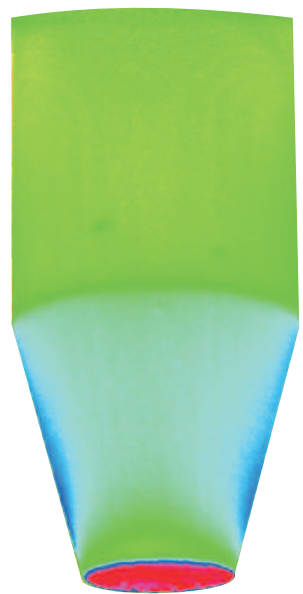

AoA 12

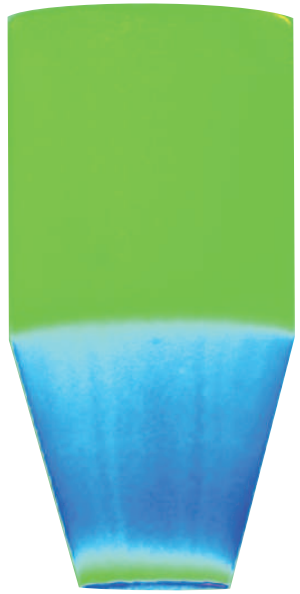

AoA 3

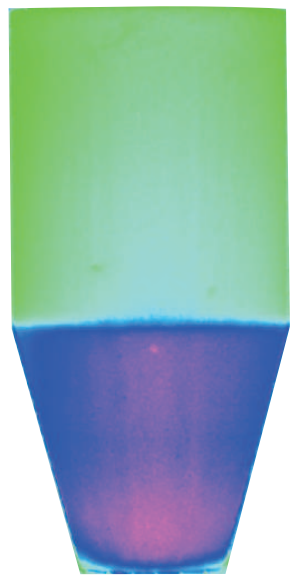

AoA -6

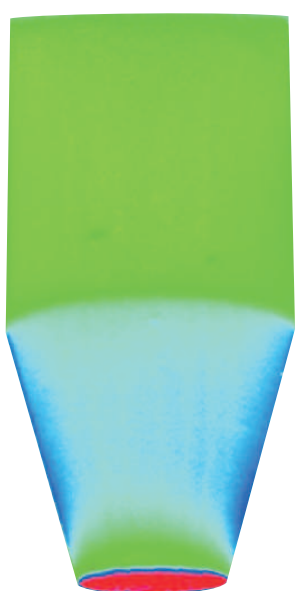

AoA 9

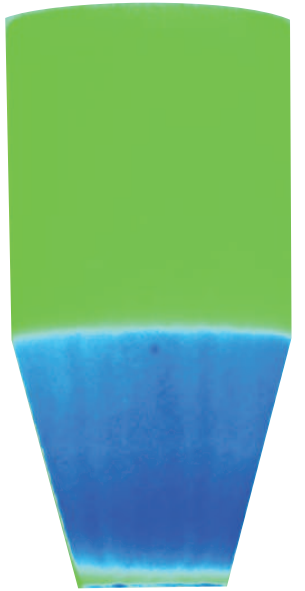

AoA 0

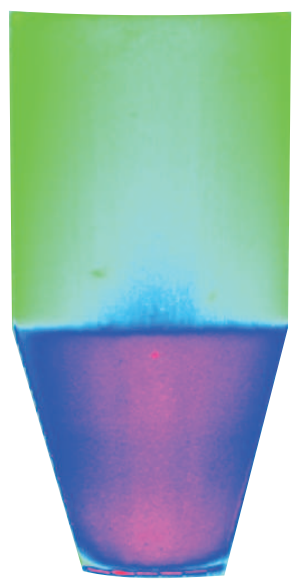

AoA -9

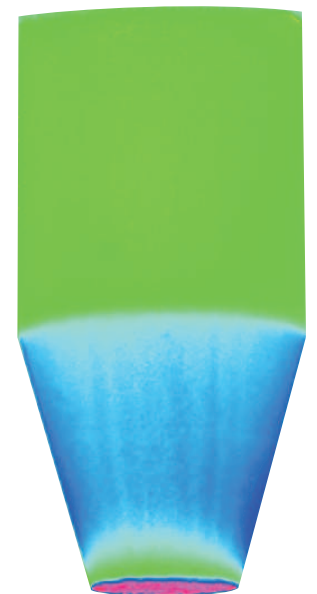

AoA 6

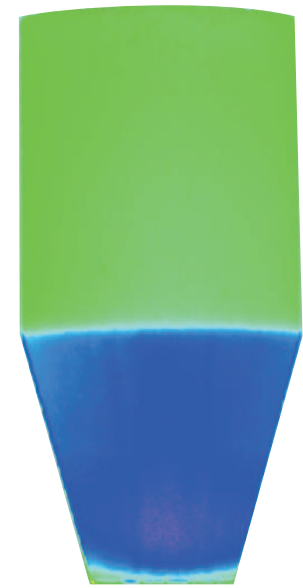

AoA -3

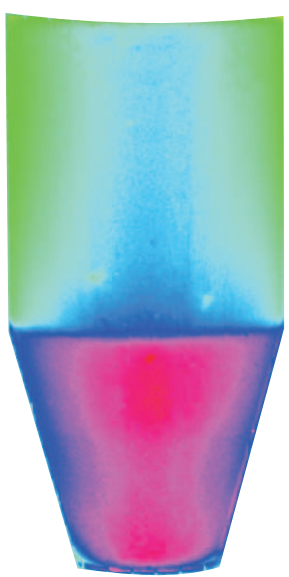

AoA -12

$\mathrm{I}_{\mathrm{ref}} / \mathrm{I}$

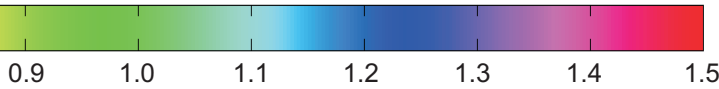

FIG. 17: Intensity ratio of truncated cone at different angles of attack. 

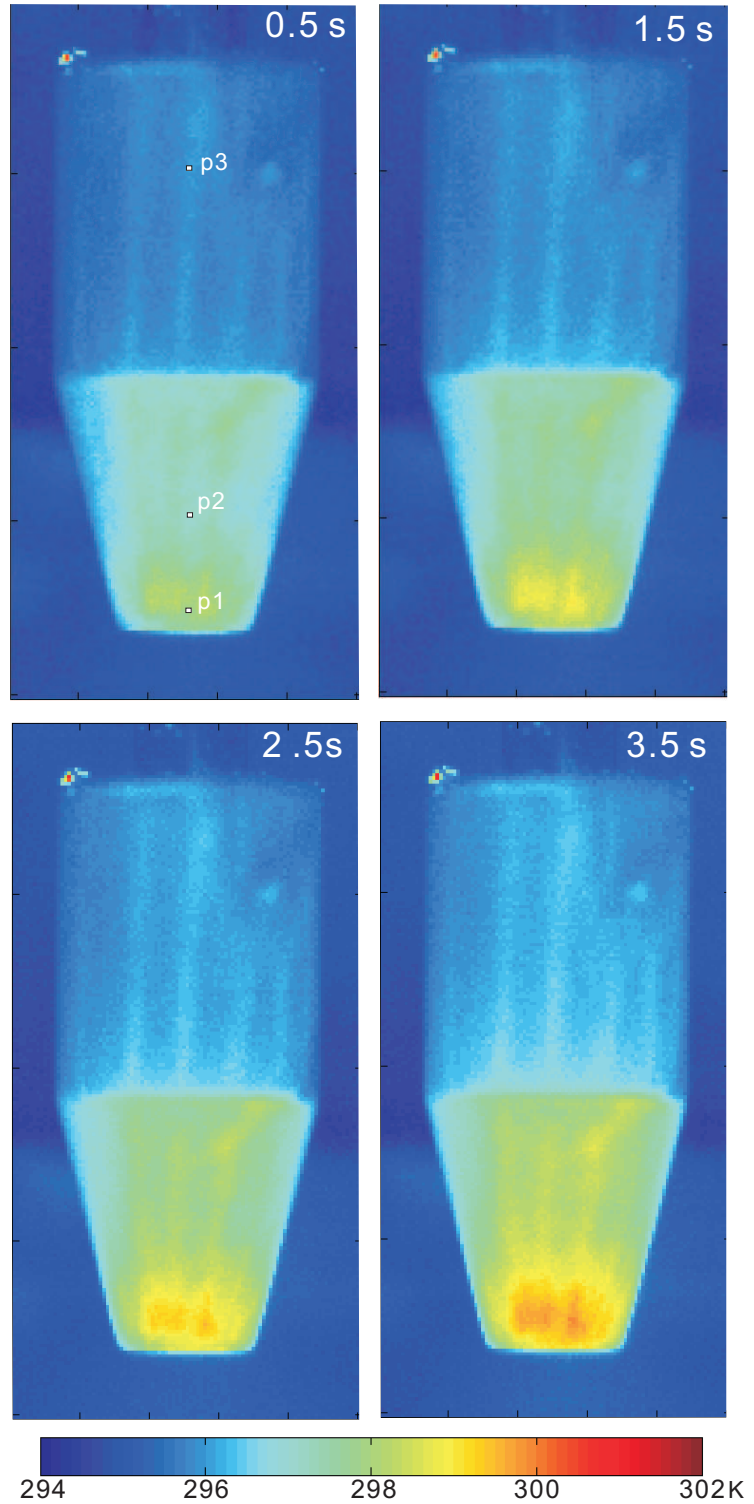

FIG. 18: Temporal evolution of surface temperature distribution on windward side, AoA -12 degrees. 


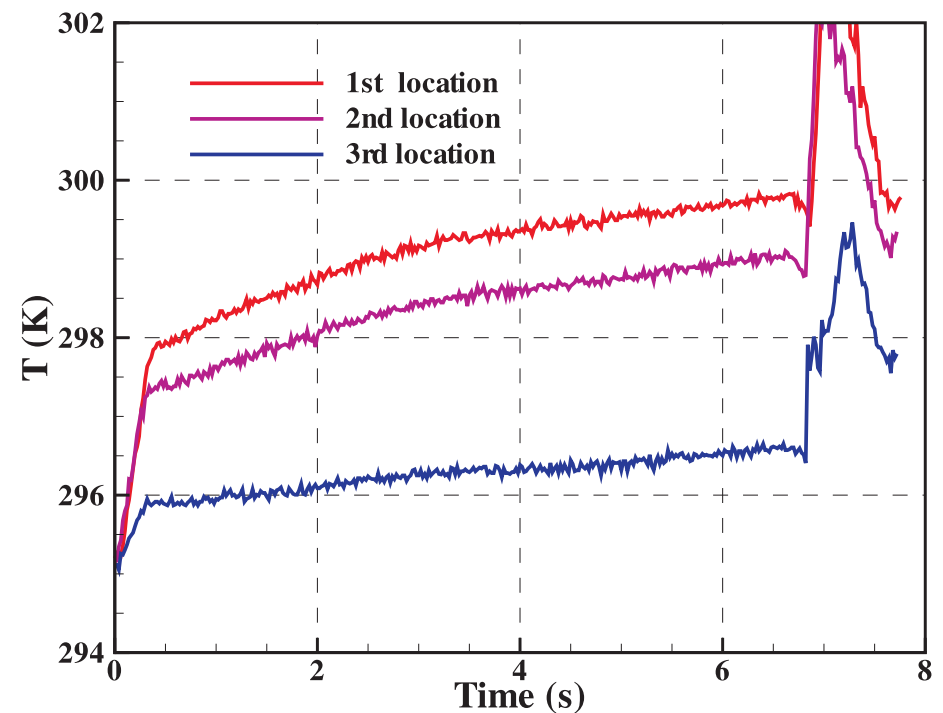

FIG. 19: Surface temperature history on windward side, AoA -12 degrees (see Figure 18 for the positions).

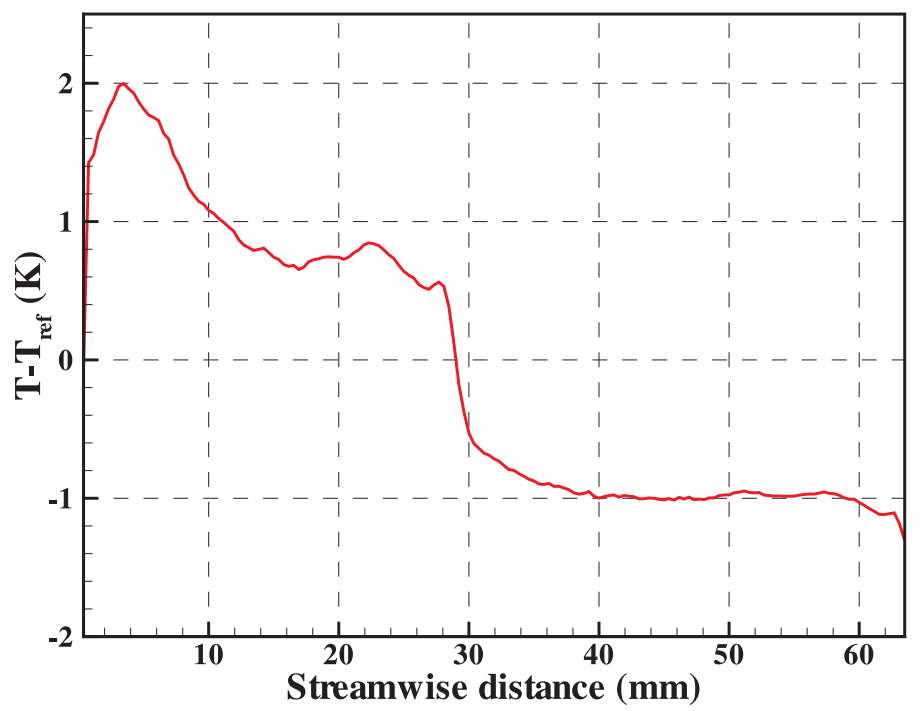

FIG. 20: Averaged temperature difference with respective to reference temperature, windward side at AoA -12 degrees 